Revista lus et Praxis, Año 22, No 1, 2016, pp. 19 - 58

ISSN 0717 - 2877

Universidad de Talca - Facultad de Ciencias Jurídicas y Sociales

Evolución Histórica del Derecho de Autor en América Latina

Alberto J. Cerda Silva

Trabajo recibido el 24 de enero y aprobado el 14 de abril de 2015

\title{
Evolución histórica del Derecho de Autor en América Latina*
}

\section{History of COPYright in LATIN America}

\begin{abstract}
Alberto J. Cerda Silva ${ }^{* *}$
RESUMEN

Los limitados estudios sobre la historia del derecho de autor en América Latina han cimentado imágenes distorsionadas sobre su evolución en la región, desde aquéllas que desconocen sus peculiaridades hasta aquéllas que niegan la existencia de una tradición regional en la protección de los creadores.

Este artículo confronta tales malentendidos revisando la evolución del derecho de autor en América Latina desde la independencia de sus países, pasando por la construcción del sistema interamericano de protección, hasta la reciente accesión de sus países a los principales instrumentos internacionales en la materia.
\end{abstract}

\section{ABSTRACT}

Limited scholarship on history of copyright in Latin America has cemented distorted images about its evolution in the region, from those that ignore its peculiarities to those that deny any regional tradition on protecting creators.

This article confronts such kind of misunderstandings by reviewing the evolution of copyright in Latin America from the time of its countries' independence, passing by the development of the Inter-American copyright system, until the recent acceding by countries to leading international instruments on the matter.

\section{Palabras CLAVE}

Derecho de Autor, Propiedad Intelectual, América Latina, Historia,

Sistema Interamericano de Derecho de Autor

KEYWORDS

Copyright, Intellectual Property, Latin America, History, Inter-American Copyright System

\footnotetext{
* El autor desea agradecer a la Fulbright Commission y a la Comisión Nacional de Ciencia y Tecnología, por su apoyo para la realización del Programa de Doctorado en Derecho en Georgetown University Law Center, 2010-2014, en el marco del cual se elaboró el presente artículo. Especiales agradecimientos por sus valiosos comentarios son debidos a Daniel Álvarez, Michael Carroll, Julie Cohen, Rebecca Tushnet, y de los colegas del programa doctoral en Georgetown University Law Center. Los errores son, por supuesto, completa responsabilidad del autor.

** Profesor Asistente de Derecho Informático, Universidad de Chile (Santiago, Chile). Licenciado en Ciencias Jurídicas y Sociales, Universidad de Chile. Magíster en Derecho Público, Universidad de Chile. LL.M. in International Legal Studies, Georgetown University. Correo electrónico: acerda@uchile.cl.
} 


\section{Introducción}

Los estudios sobre la historia del derecho de autor en América Latina son bastante limitados, especialmente en lo concerniente a su desarrollo durante el siglo XIX. ${ }^{1}$ Aun cuando en los años recientes una nueva generación de estudiosos ha trabajado en revertir tal carencia, existe aún una sentida ignorancia en la materia, la cual ha cimentado diferentes malentendidos en cuanto a la evolución del derecho de autor en la región. Este sentido déficit ha conducido a algunos autores a presuponer que el derecho de autor en América Latina carece de toda peculiaridad respecto del sistema europeo, en lo que ha sido denunciado como "un imaginario armonizado sobre la evolución del sistema de propiedad intelectual", 2 que desmerece la identidad, la experiencia, y las capacidades locales. Este malentendido entronca con aquella tendencia a visualizar el derecho latinoamericano como un simple remedo, una copia imperfecta, del derecho europeo o estadounidense. ${ }^{3}$ Otros autores han llegado a presuponer que la región "no posee tradición alguna en la protección de los derechos de propiedad intelectual", ${ }^{4}$ y que, por ende, el derecho de autor sólo ha cobrado vida en la región con la reciente oleada de acuerdos internacionales en la materia. Esta narrativa suele conectarse con aquélla que presupone que los países de la región eran ajenos a la comunidad internacional en la reflexión de estos temas, ${ }^{5}$ manteniéndose obtusamente al margen hasta hace pocos años. Este artículo tiene por objetivo confrontar esos malentendidos, mediante la revisión de la evolución del derecho de autor en América Latina desde los tempranos días que sucedieron a la independencia de sus países, pasando por la construcción de un sistema regional de protección, hasta la reciente accesión de los países hacia estándares internacionales en la materia.

La primera sección de este artículo se remonta a los orígenes de la protección autoral en los países de América Latina. Inmediatamente después de sus independencias y tras una breve subsistencia del régimen colonial, los países de la región adoptaron legislación local. Pero, dadas las limitaciones de la protección simplemente local, hacia fines del siglo XIX, los países avanzaron en la construcción de un sistema regional de protección a los derechos autorales

\footnotetext{
${ }^{1}$ Roldán (2003), p. 9. del primero en torno al Convenio de Berna.

3 Rodríguez (2011), p. 12.

4 Buscaglia y Long (1997), p. 4. Véase también Sánchez (1997), p. 34.

5 Plazas (1984), pp. 102-103.
}

2 PABÓn (2010), p. 23; y PABÓn (2009), p. 60. Véase Fragoso (2012), pp. 195-199, quien presupone una temprana división entre la tradición de los derechos de autor y del copyright, así como la uniformidad 
basado en diversos tratados, el cual es analizado en la segunda sección de este artículo, al que denominamos sistema interamericano de derecho de autor, porque él no se circunscribía a los países latinoamericanos. De hecho, Estados Unidos fue uno de sus grandes promotores y adhirió a sus principales instrumentos. A través de los años, el sistema interamericano demostró ser más flexible, para satisfacer las necesidades de los países que eran parte de él, de lo que su competencia: el sistema europeo de protección de los derechos de autor, basado en el Convenio de Berna y sus sucesivas revisiones. Esto hacía complicada la accesión de los países de América Latina al Convenio de Berna.

Sin embargo, la existencia de dos sistemas paralelos de protección dificultaba la obtención de una protección verdaderamente universal para los creadores; esta situación se agravó a mediados del siglo XX, a raíz de los devastadores efectos de la Segunda Guerra Mundial en Europa y la emergente descolonización de África y Asia. Como resultado de ello, los países trabajaron en la armonización de los sistemas existentes. La tercera sección de este artículo describe este proceso usualmente denominado de internacionalización de los derechos de autor, aun cuando sería preferible denominarle de europeización ya que la convergencia normativa se produce en torno al sistema europeo, y en especial como los países de América Latina progresivamente vinieron a ser partes del Convenio de Berna y demás instrumentos subsecuentes en materia de derechos de autor. La plena eficacia de dichos instrumentos internacionales ha requerido de su implementación normativa en el derecho interno de los países de la región, un proceso que, al igual que los nuevos compromisos internacionales en materia de derecho de autor asumidos recientemente por países de la región a través de acuerdos bilaterales de comercio, no será objeto de este artículo, sino de un trabajo posterior.

\section{Los inicios de la protección autoral en América Latina}

Durante el período colonial, la economía de América Latina se basó en la explotación de sus recursos naturales, a través de la agricultura y minería. ${ }^{6}$ La tierra fue asignada a los colonos, mientras la población indígena y esclava proveyeron mano de obra para el funcionamiento de la economía colonial. La producción local satisfacía el consumo doméstico, pero un significativo monto de la producción, especialmente minera, era remitido a las metrópolis, España y Portugal, que se encargaban de ejercer un estricto control sobre el comercio en los territorios de la región, gracias a una extensa red de organismos burocráticos.

\footnotetext{
${ }^{6}$ Franko (2007), p. 37. Véase también, Brading (1984), pp. 389-439; Manzuy-Diniz Silva (1984), pp. 486-508; KeEn y Haynes (2004), pp. 85-90.
} 
El monopolio impuesto por la Corona española concentró tanto la compra de bienes locales como la venta de determinados productos en los asentamientos coloniales. ${ }^{7}$ Un virtual monopolio fue también impuesto en materia cultural. ${ }^{8}$ A pesar de disponer de ciertas capacidades de impresión, las colonias estaban sujetas a la censura de la Iglesia Católica y de la Corona, ${ }^{9}$ la que era aún más fuerte que en la propia Europa, lo cual reducía la impresión a textos de naturaleza religiosa. ${ }^{10}$ Sin embargo, la impresión local era aún extremadamente limitada y las colonias dependían de editores españoles para satisfacer sus necesidades culturales, ${ }^{11}$ a lo cual, más tarde en el siglo XVIII, se había de agregar el contrabando de libros, el que también traería las ideas de la llustración a las Américas, las cuales, en último término, habían de cimentar las bases de la emancipación de los países de la región.

Tras sus independencias, incapaces de concretizar el sueño bolivariano de una sola nación, las antiguas colonias españolas lucharon por la consolidación de las nuevas naciones, gobiernos, y regímenes políticos. ${ }^{12}$ La transición del Brasil hacia su independencia fue notoriamente posterior, pero pacífica y rápida comparada con el proceso vivido por las colonias de España. ${ }^{13}$ En el plano económico, tras un período de estancamiento que siguió a la guerra por la independencia, ${ }^{14}$ hacia mediados del siglo XIX, los países de América Latina habían adoptado las ideas librecambistas de Adam Smith y sobre ventajas comparativas de David Ricardo, ${ }^{15}$ redoblando los esfuerzos de sus economías en la explotación de sus recursos naturales. ${ }^{16}$ Naturalmente esto explica por qué la propiedad raíz y no el capital ni el conocimiento, incluida la propiedad intelectual, era la principal preocupación de los juristas de la época. Así, por ejemplo, incluso siendo consciente de la relevancia de proteger la propiedad literaria y artística, ${ }^{17}$ Andrés Bello, autor del

7 Keen y Haynes (2004), pp. 90-91.

${ }^{8}$ Keen y Haynes (2004), p. 143.

9 Keen y Haynes (2004), p. 147.

10 Lafaye (1984), pp. 663-704.

11 Lafaye (1984), p. 698; Bethell (1984a), pp. 705-707.

12 Glade (1984), pp. 1-7. Véase también, Clayton y Conniff (2005), pp. 72-107; Bulmer-Thomas (2003), pp. 19-45.

13 Confróntese Rodríguez (2008), pp. 195-214, con Bethell (1984b), p. 195. Véase también Chasteen (2000), pp. 16-21; y SKIDMORE et al. (2010), pp. 27-36.

14 Halperín Donghi (1984), pp. 329-330. Véase también Lauria-Santiago (2008), pp. 264-284.

15 SKIDMORE et al. (2010), pp. 353-358.

16 Glade (1984), pp. 9-19. Véase Dean (1984), pp. 693-700; y Meade (2010), pp. 103-133. Véase también, KeEN y HaYNeS (2004), pp. 217-220; y SKIDMORE et al. (2010), pp. 37-40.

17 BelLo (1932), pp. 467-474. 
influyente Código Civil que sería adoptado por varios países de la región como propio, ${ }^{18}$ no reglamentó los derechos de autor y apenas los refirió a una legislación especial. ${ }^{19}$ Sin embargo, incluso no siendo una preocupación principal, la protección de los derechos de autor tiene una larga tradición en los países de América Latina cuyo origen se remonta a los tempranos días que siguieron a sus independencias, cuando los países brindaron tanto protección constitucional como legal a los derechos autorales.

Los países de América Latina adoptaron constituciones tan pronto la independencia de sus colonizadores se consolidó, y aun antes en algunos casos. Cláusulas relativas al derecho de autor se incluyeron en ellas, a pesar de las limitadas capacidades de impresión de la región. ${ }^{20}$ En algunos casos, dichas disposiciones constitucionales seguían el modelo estadounidense que supone brindar protección a efectos de alentar el progreso científico y artístico, difiriendo al poder legislativo una decisión sobre la materia, ${ }^{21}$ tal como hacía la Constitución de México de 1824, ${ }^{22}$ y la Constitución de Argentina de 1819. ${ }^{23}$ Otros países inicialmente consideraron cláusulas similares, pero finalmente adoptaron el modelo francés de derechos de autor que reconoce dichos derechos como inherentes a la persona del creador. ${ }^{24}$ Este último fue el caso de la Constitución del Perú de $1828,{ }^{25}$ si bien su Constitución de 1856 otorgó a los autores derechos exclusivos

\footnotetext{
${ }^{18}$ JAKSIC (2011), pp. 226-229.

19 Código Civil (Chile), artículo 584: "Las producciones del talento o del ingenio son una propiedad de sus autores. Esta especie de propiedad se regirá por leyes especiales".
}

20 Véase Medina (1958); Howsam y Raven (2011).

${ }^{21}$ Constitución de los Estados Unidos de América, artículo I, sección 8, cláusula 8: "The Congress shall have the Power to promote the Progress of Science and useful Arts, by securing for limited Times to Authors and Inventors the exclusive Right to their respective Writings and Discoveries".

${ }^{22}$ Constitución Federal de los Estados Unidos Mexicanos, 4 de octubre de 1824, artículo 50: "Las facultades exclusivas del congreso general son las siguientes: 1. Promover la ilustración, asegurando por tiempo limitado derechos exclusivos a los autores por sus respectivas obras...". Véase RABASA (2000), p. 15; y SERRANO (1998), pp. 38-39. A diferencia de la constitución, la ley de derechos autorales siguió una perspectiva bastante más conservadora, garantizando derechos exclusivos, absolutos, y perpetuos a los autores sobre las obras, análogos a los derechos concedidos en el derecho romano al propietario de bienes corporales. Véase Noriega (1907), pp. 7-8; Ocampo (1900), pp. 13-17.

${ }^{23}$ Constitución de las Provincias Unidas de Sudamérica, 22 de abril de 1819, artículo 44: consignando entre las atribuciones del Congreso "Asegurar a los autores o inventores de establecimientos útiles privilegios exclusivos por tiempo determinado". La cláusula sobre derechos de autor de la constitución de 1819 pasó a la constitución de 1826 y de ésta a la de 1853. Véase Zeballos (1911), pp. 1-2.

${ }^{24}$ Ginsburg (1990).

${ }^{25}$ Constitución Política de la República Peruana 1828, de 18 de marzo de 1828, artículo 48: "Son atribuciones del Congreso: 19.- Acordar patentes por tiempo determinado a los autores introductores de alguna invención o mejora útil a la República". 
de propiedad sobre sus creaciones y refería al legislativo su implementación. ${ }^{26}$ De modo similar, un primer borrador de la Constitución de Chile de 1833 seguía el modelo estadounidense, ${ }^{27}$ pero finalmente confirió derechos de propiedad a los autores sobre sus creaciones, siguiendo el modelo continental de los derechos de autor, ${ }^{28} \mathrm{el}$ cual persiste hasta la constitución vigente en nuestros días. ${ }^{29}$ Venezuela reconoce los derechos de autor desde su Constitución de 1830, ${ }^{30}$ siguiendo también la tradición francesa. ${ }^{31}$ Entretanto, en la intensa vida constitucional de los años que siguieron a la independencia de Colombia, es posible encontrar tempranas referencias a la protección de la propiedad intelectual, ${ }^{32}$ pero sólo la Constitución de 1858 se refiere expresamente a los derechos de autor al conferir al presidente la facultad de garantizar su protección. ${ }^{33}$ Por su parte, a diferencia de los otros países latinoamericanos, Brasil no brindó protección constitucional a los derechos de autor sino hasta finales del siglo XIX, pero, en cambio, proveyó ésta a través del derecho penal. ${ }^{34}$

El otorgamiento de protección constitucional a los derechos de autor fue relevante. Este permitía a los tribunales Ilenar los vacíos de la ley vigente, si ésta resultaba insuficiente para proteger los derechos de los creadores. ${ }^{35}$ Por ejemplo, en el caso de Hernández v. Barbieri Hermanos, a pesar de la ausencia de disposiciones de rango legal aplicables, la Corte Suprema de Justicia de Argentina

${ }^{26}$ Constitución de la República Peruana, dada el 13 de octubre de 1856 y promulgada en 19 del mismo mes, artículo 27: "la ley asegura a los autores o introductores de invenciones útiles, la propiedad exclusiva de ellas, o la compensación de su valor si convinieron en que se publiquen".

27 Mirosevic (2007), pp. 64-65.

${ }^{28}$ Constitución Política de la República de Chile, de 25 de mayo de 1833, artículo 152: "Todo autor o inventor tendrá la propiedad exclusiva de su descubrimiento o producción por el tiempo que le concediere la ley, y si ésta exigiere su publicación, se dará al inventor la indemnización competente".

${ }^{29}$ Mirosevic (2007), pp. 65-77.

${ }^{30}$ Constitución del Estado de Venezuela de 1830, artículos 161 y 217. Este último disponía que: "Todo inventor tendrá la propiedad de sus descubrimientos y de sus producciones. La ley le asignará un privilegio temporal, ó resarcimiento de la pérdida que tenga en el caso de publicarlo".

31 Fariñas (2009), p. 14. Véase también AnTeQuera (1977), p. 20.

32 Peña y Carmona (2011), p. 23; y Rengifo (1996), p. 25.

33 Constitución Política para la Confederación Granadina, Bogotá, 29 de mayo de 1858, artículo 43: "Son atribuciones del Presidente de la Confederación: 14. Conceder patentes garantizando por determinado tiempo la propiedad de las producciones literarias de las invenciones útiles aplicables a nuevas operaciones industriales, o a la perfección de las existentes, a los autores de dichas producciones o invenciones".

34 Mizukami (2007), pp. 286-290. Véase también, Paranagua y Branco (2009), pp. 18-20; Mizukami et al. (2010), pp. 42-48.

${ }^{35}$ Véase Rodrícuez (1929), pp. 35-36. 
otorgó indemnización de perjuicios a favor del demandante, el escritor José Hernández, sobre la base de que la impresión de copias no autorizadas de su obra maestra "Martin Fierro", la obra cumbre de la poesía argentina del siglo XIX, infringía las normas constitucionales sobre derechos de autor. ${ }^{36}$ En otros términos, ante la ausencia de disposiciones legales, las normas constitucionales proveían cierta protección. Adicionalmente, tal como lo prueba la temprana adopción de normas legales en la materia, las cláusulas de protección constitucional a los derechos de autor también Ilamaban la atención del legislativo en orden a adoptar normas específicas a su respecto.

En adición a la protección constitucional de los derechos de autor, varios países de América Latina adoptaron legislación específica en la materia. ${ }^{37} \mathrm{Al}$ comienzo, los recientemente independizados países continuaron usando las leyes de sus colonizadores ${ }^{38}$ las que progresivamente fueron reemplazadas por legislación propia. ${ }^{39}$ Por ejemplo, México aplicó la normativa española hasta 1846, cuando adoptó su propia ley sobre derechos autorales, ${ }^{40}$ tras un bullado caso que probó la ineficacia de las reglas coloniales. ${ }^{41}$ Otros países aprobaron leyes en la materia aun más temprano; este fue el caso de Chile (1834), ${ }^{42}$ Colombia (1834), ${ }^{43}$ Venezuela (1839) ${ }_{1}^{44}$ y Perú (1849) ${ }^{45}$ Otros países de la región aprobaron legislación más tarde, durante el siglo XIX. En general, estas leyes sobre derechos de autor garantizaban a los creadores locales derechos exclusivos sobre la impresión de las obras por un corto período tras la publicación de aquéllas y el cumplimiento de ciertas formalidades, tales como el registro y el depósito de ejemplares de las obras en cuestión.

\footnotetext{
${ }^{36}$ Corte Suprema de Justicia de Argentina, Hernández v. Barbieri Hermanos, 24 de noviembre de 1885, Fallos XXIX, 148. Véase BaIRes (1897), pp. 19-26, y 55-87.

37 Véase PABÓN (2010), pp. 82-88.

38 Véase Martínez (1982), pp. 28-35.

${ }^{39}$ Oquendo (2006), p. 114; Mirow (2004), pp. 125-131. Véase también JaksiC (2011), pp. 207 y ss.; RODRÍGUEZ (2012), p. 146.

40 Mateos (1887), pp. 9-10; y Serrano (1998), pp. 39-41.

${ }^{41}$ Véase PABÓn (2010), pp. 81-82.

42 Ley de Propiedad Literaria y Artística, publicada en el diario El Araucano, 24 de Julio de 1834 (Chile). Véase GuZMÁN (2005), p. 58.

43 Ley de 10 de mayo de 1834, que asegura por cierto tiempo la propiedad de las producciones literarias y algunas otras (Colombia). Véase PABÓN (2010), pp. 91-118.

${ }^{44}$ Ley 19 de abril de 1939 asegurado la propiedad de las producciones literarias (Venezuela).

45 Ley de Propiedad Intelectual, de 3 de noviembre de 1849 (Perú).
} 
Aquellos países que no disponían de leyes especiales y comprehensivas sobre derechos autorales también proveían protección. Brasil, por ejemplo, no adoptó su primera ley especial en la materia sino hasta 1898, pero ya desde 1830 su legislación criminal proveía protección a las obras de los creadores. ${ }^{46}$ Argentina es probablemente el caso más extremo, porque a lo largo del siglo XIX careció de una regulación sistemática de los derechos autorales y apenas disponía de un conjunto fragmentario de normas hasta la adopción de una ley especial en $1910,{ }^{47}$ lo cual ha conducido a algunos autores a afirmar erradamente que el país no brindaba protección a los autores. ${ }^{48}$ La ausencia de una ley especial, sistemática, y coherente sobre derechos de autor, sin embargo, limitaba la protección a abusos escandalosos y generaba cierta incertidumbre jurídica. ${ }^{49}$

A través del siglo XIX, los países de América Latina no sólo adoptaron normas constitucionales y legales sobre protección de los derechos autorales, sino que también consolidaron una transición desde el régimen colonial de privilegios a una normativa sobre propiedad literaria con fuertes raíces en el derecho natural. ${ }^{50}$ De hecho, la mayor parte de los estudiosos de la región no visualizaban diferencias significativas entre dicha propiedad literaria y la propiedad sobre bienes tangibles, salvo su limitación temporal, que era apenas aceptada por razones prácticas de interés social. ${ }^{51}$ Hacia finales del siglo, la literatura latinoamericana especializada había adoptado conceptos más comprensivos para referirse a esta área del derecho, tales como propiedad intelectual o derechos de autor, ${ }^{52}$ los cuales aún prevalecen en la doctrina local.

El desarrollo normativo y teórico del derecho de autor en América Latina contrasta con las limitadas capacidades de la región para producir contenido susceptible de protección autoral. Por un lado, las ediciones locales eran escasas y reducidas, ${ }^{53}$ mientras las obras de autores latinoamericanos eran de difícil obtención inclusive dentro de la región. ${ }^{54}$ Por otro lado, las librerías

\footnotetext{
${ }^{46}$ Véase Mizukami (2007), pp. 287-288.

47 Zeballos (1911), pp. 1-7. Véase Bellido (2011), pp. 93-98. Véase también Quesada (1904), pp. 132-231.

${ }^{48}$ RAMA (1982), p. 176.

49 Singer (1909), p. 7. Véase también Baires (1897), pp. 19-53.

50 Véase Lastarria (1906), pp. 455-460; Reyes (1857); Baires (1897), pp. 22 y 25.

51 Véase también Mestre (1863).

52 Mestre (1863); Oyuela (1889), pp. 397-502; Martins (1906), pp. 17 y ss. Recientemente, Jhonny Pabón ha provisto una documentada obra en que considera la transición desde el régimen de privilegios al de propiedad intelectual en la Colombia del siglo XIX. Véase PABÓN (2010).

53 TORnero (1872), pp. 99-100.

${ }^{54}$ Matta (1873), p. 1; Alcover (1912), pp. 5-10.
} 
también eran escasas, y básicamente comercializaban obras producidas en ultramar a altísimos precios. ${ }^{55}$ Diversas razones pueden explicar el poco alentador estado de estos asuntos en la región, tales como los deficientes medios de comunicación y transporte, la ausencia de producción local de papel y otros insumos para la impresión, y el reducido tamaño de los mercados locales, entre otros. Desde mediados del siglo XIX, los juristas de la época ya anticipaban la necesidad de disponer de protección más allá de las fronteras de cada país a efectos de promover el progreso de las artes y las ciencias, si bien alertaban sobre la relativa inconveniencia de proteger la producción editorial de potencias extranjeras. ${ }^{56}$

Como en otros países, la primera legislación interna sobre derechos autorales de América Latina proveía protección sólo dentro de las fronteras a los nacionales o habitantes del país respectivo. ${ }^{57}$ Por su puesto, ésta no era una limitación exclusiva de las normas sobre derecho de autor, sino una característica común al derecho interno basado en la soberanía de los estados. Inclusive si un país confería derechos a los creadores extranjeros, esto no garantizaba que los creadores locales gozarían de similar protección en otros países. Más aún, disponer de protección sólo para los creadores nacionales permitía la importación de libros en español hacia los países de América Latina, provenientes principalmente de Estados Unidos y Francia, ${ }^{58}$ países que no protegían las obras exportadas. Este fenómeno, conocido como "piratería situacional", porque el comportamiento legalizado bajo la ley de un país es ilegal en otros, ${ }^{59}$ fue sumamente relevante en América Latina para satisfacer ciertas necesidades culturales, especialmente considerando las limitadas capacidades de producción existentes en la región. ${ }^{60}$

Para efectos de obtener protección más allá de las fronteras de un estado, los países suscribieron tratados que ofrecían protección recíproca, es decir, un país extendía el amparo de su ley a los creadores nacionales de otro país a

55 Tornero (1872), p. 190; Martínez (1982), pp. 149-152; Lastarkia (2001), p. 38.

56 Sarmiento (1896), pp. 59-68; Reyes (1857), pp. 341-342; Baires (1897), pp. 98-122.

57 Rukavina (2010), p. 57. Véase PabÓn (2010), pp. 83-85.

${ }^{58}$ Véase Clark (1973), p. 39; Fernández (1998), pp. 200-209; Khan (2007), pp. 21-54. Véase también PABÓN (2010), pp. 85-90.

${ }^{59}$ Balázs (2011), p. 408. Véase Drahos y Braithwaite (2002), pp. 23-32, quienes sostienen que históricamente la expresión piratería es más que un término jurídico preciso "una herramienta retórica particularmente efectiva" y una "práctica cotidiana de todos los participantes" en el comercio internacional de libros. Véase también Johns (2009); Johns (2010), pp. 44-52, quien destaca la evolución histórica de la expresión piratería en el comercio de libros entre los siglos XVII y XIX.

60 Taubert (1976), pp. 11-12; EnríQuez (2008), p. 16. 
cambio de análogo beneficio para sus propios nacionales en aquel otro país. Sin embargo, las aún jóvenes repúblicas de América Latina no tenían numerosos tratados, ${ }^{61}$ a diferencia de Europa, donde una extensa red de acuerdos entre países intentaba proveer protección a los autores a través de las fronteras. ${ }^{62}$ Por otro lado, los tratados con oferta de reciprocidad no constituían una solución de largo plazo, pues estaban Ilenos de complejidades técnicas y diplomáticas, tenían diferencias significativas en su aplicación, y carecían de un estándar de protección común. Esto hacía necesario trabajar en alguna solución de armonización internacional que garantizase un nivel de protección similar a los creadores, cualquiera fuese su nacionalidad, residencia, o lugar de publicación.

\section{América Latina bajo el Sistema Interamericano de Derechos de Autor}

Hacia finales del siglo XIX, dos sistemas competían por lograr la protección de las obras a través de las fronteras: el europeo, basado en el Convenio de Berna y sus sucesivas revisiones, y el interamericano, basado en el Tratado de Montevideo y varios otros instrumentos de que eran parte los países del continente americano.

En 1886, los países europeos convinieron estándares mínimos de protección legal para las obras mediante la adopción del Convenio de Berna para la Protección de las Obras Literarias y Artísticas. ${ }^{63}$ El Convenio creaba una Unión de países que proveería protección a los derechos de autores y editores de cualquier obra literaria, científica, o artística de los países parte. ${ }^{64}$ La protección se basaba en trato nacional, esto es, un autor extranjero disfrutaría de los mismos derechos que la legislación nacional de uno de los estados partes garantizaba a sus propios nacionales, excepto respecto del plazo de protección, el cual no excedería aquél provisto en el país de origen. ${ }^{65}$ Sin embargo, la protección estaba sujeta a que se cumpliera con los requisitos y formalidades previstos en

\footnotetext{
${ }^{61}$ En términos relativos, la carencia de tratados garantizando reciprocidad no constituía un problema para América Latina en cuanto países esencialmente importadores de obras; de hecho, ello permitía a los nuevos países independientes sacar ventajas de la producción cultural de sus antiguos colonizadores. Esto, a su vez, limitaba las posibilidades de estos últimos para retaliar en contra de los países de América Latina. Véase AnsORenA (1894), pp. 244-245.

${ }^{62}$ Confróntese Ansorena (1894), p. 243; García (1901), pp. 404-499 con Lipszyc (1998a), pp. 38-39. Véase también FERNÁNDEZ (1998), pp. 200-209.

${ }^{63}$ Convenio de Berna para la Protección de las Obras Literarias y Artísticas, 9 de septiembre de 1886 (Convenio de Berna-Acta de Berna de 1886).

${ }^{64}$ Convenio de Berna-Acta de Berna de 1886, artículos 1 a 4.

${ }^{65}$ Convenio de Berna-Acta de Berna de 1886, artículo 2.
} 
el derecho interno del país de origen de la obra; ${ }^{66}$ en consecuencia, el registro podría aún ser necesario, como de hecho lo era en Francia, España, y Portugal. ${ }^{67}$ A pesar de haber sido negociado sólo por un puñado de países, el Convenio de Berna estaba explícitamente abierto a su accesión por otros países, en lo que constituía una invitación abierta a las antiguas colonias de los países europeos. ${ }^{68}$

Sucesivas revisiones del Convenio de Berna extendieron los derechos de autor, pero no proveyeron de flexibilidades para satisfacer necesidades de interés público. La revisión de Berlín de 1908 es probablemente la más influyente, ${ }^{69}$ pues derogó la exigencia de formalidades -tales como el registro, depósito, o inclusión de aviso de derechos autorales- para efectos de obtener la protección internacional, mediante el establecimiento de un sistema de protección automático. ${ }^{70}$ La revisión de Berlín estableció, además, un plazo mínimo de protección -la vida del autor más cincuenta años tras su muerte- ${ }^{71}$, el cual devendría en obligatorio a partir de la revisión de Bruselas de $1948 .^{72}$ Por su parte, la revisión de Roma de 1928 reconoció los derechos morales de autoría e integridad. ${ }^{73}$ Las flexibilidades que permitirían el uso de obras sin la autorización de los titulares de derechos autorales, en cambio, eran dejadas a su determinación por el derecho interno de los estados partes. ${ }^{74}$ Como resultado de

\footnotetext{
${ }^{66}$ Convenio de Berna-Acta de Berna de 1886, artículo 2.
}

${ }^{67}$ De hecho, la exigencia de formalidades permaneció en pie en la Europa del siglo XIX, pero progresivamente fueron atemperadas, no por razones filosóficas asociadas al derecho de autor, sino por razones prácticas, liberando a los titulares de derechos de la necesidad de satisfacer una multiplicidad de formalidades para obtener protección en diferentes países. Véase Gompel (2010), pp. 157-206. Véase también, Danvila y Collado (1882), pp. 743-877.

${ }^{68}$ Convenio de Berna-Acta de Berna de 1886, artículos 18 y 19.

${ }^{69}$ Convenio de Berna para la Protección de las Obras Literarias y Artísticas, revisado en Berlín, 13 de noviembre de 1908, (Convenio de Berna-Acta de Berlín de 1908).

${ }^{70}$ Convenio de Berna-Acta de Berlín de 1908, artículo 4. En estricto sentido, el Convenio de Berna no deroga la exigencia de formalidades en el derecho interno de los países parte, sino que prescinde de ellas a efectos de proveer protección a los autores de otros países, esto es, permite formalidades en los países de origen; sin embargo, por razones obvias, los países optan por derogar las formalidades tanto para sus propios nacionales como para los extranjeros. Véase Gompel (2010), p. 203. En contra, LADAS (1940-1941), p. 288.

71 Convenio de Berna-Acta de Berlín de 1908, artículo 7.

72 Convenio de Berna para la Protección de las Obras Literarias y Artísticas, revisado en Bruselas, 26 de junio de 1948 (Convenio de Berna-Acta de Bruselas de 1948), artículo 7.

${ }^{73}$ Convenio de Berna para la Protección de las Obras Literarias y Artísticas, revisado en Roma, 2 de junio de 1928 (Convenio de Berna-Acta de Roma de 1928), artículo 6 bis.

${ }^{74}$ Véanse Convenio de Berna-Acta de Berna de 1886, artículos 7 y 8; Convenio de Berna-Acta de Berlín de 1908, artículos 9 y 10; Convenio de Berna-Acta de Roma de 1928, artículos 9 y 10; y Convenio de Berna-Acta de Bruselas de 1948, artículos 10 y 10 bis. 
esto, a mediados del siglo recién pasado, el Convenio de Berna había creado un sistema de protección automático de los derechos de autor que garantizaba un catálogo de derechos patrimoniales y morales a los autores de cualquier obra, por sus vidas y cincuenta años adicionales.

El Convenio de Berna era una iniciativa de los "países civilizados", como expresaba la invitación del gobierno suizo a la reunión en que fue suscrito, para alcanzar protección internacional de los derechos de autor. ${ }^{75}$ De hecho, los países parte fueron los principales poderes coloniales de la época: Bélgica, Francia, Alemania, Italia, España, Suiza y el Reino Unido. En verdad había entre los países signatarios algunos que no eran europeos -en concreto, Haití, Liberia y Túnez-, pero su participación estaba supeditada a su estatus colonial y tenía por objeto fortalecer la posición francesa. ${ }^{76}$ Como resultado de esto, el Convenio reflejaba los intereses de los países europeos por lograr un adecuado nivel de protección, en especial respecto de su potencial mercado colonial.

Los países del continente americano no accedieron al Convenio de Berna sino que, en cambio, establecieron un sistema paralelo que brindaba protección internacional a los derechos de autor a través de un régimen regional. Este proceso comenzó con la adopción del Tratado de Montevideo de 1889, ${ }^{77}$ el cual reconoció varios derechos patrimoniales exclusivos en una amplia categoría de obras. ${ }^{78}$ Los países parte proveerían protección a los autores de otro de los países partes de acuerdo al derecho interno aplicable en el país de origen (lex loci originis). ${ }^{79}$ Sin embargo, el plazo de protección era una decisión discrecional de las partes y podía estar limitado al plazo más breve de protección provisto en el país de origen. ${ }^{80}$ A diferencia del Convenio de Berna, el Tratado de Montevideo no creó una Unión y, en consecuencia, su accesión por otros países estaba sujeta a la aceptación de los países parte del tratado. ${ }^{81}$

La documentación disponible no específica las razones exactas por qué los países americanos rechazaron ser partes del Convenio de Berna y, en cambio,

75 UChtenhagen (1998), p. 74.

76 Uchtenhagen (1998), p. 80.

77 Tratado sobre Propiedad Literaria y Artística, firmado en Montevideo el 11 de enero de 1889 (Tratado de Montevideo).

78 Tratado de Montevideo, artículos 3 y 5.

79 Tratado de Montevideo, artículo 2. Véase Belıido (2011), pp. 27-41.

80 Tratado de Montevideo, artículo 4.

${ }^{81}$ Tratado de Montevideo, artículos 13 y 16. Véase LiPSZYC (1998b), pp. 38-39; y LaDAS (1938), pp. 636 y 654. Véase también BelLido (2011), pp. 49-67, quien describe las dificultades políticas y diplomáticas que enfrentaron España y Francia a efectos de obtener su aceptación por algunos de los países partes del Tratado de Montevideo. 
adoptaron su propio sistema regional de protección de los derechos autorales. El afán no era ciertamente desconocer derechos a los creadores, quienes gozaban de reconocimiento de sus derechos en diversas constituciones y normas legales a través de la región. ${ }^{82}$ Todavía más, en varios aspectos la protección provista por el Tratado de Montevideo era superior a la provista por el Convenio de Berna. ${ }^{83}$ El Tratado de Montevideo no proveía derechos exclusivos sobre la ejecución y representación de obras musicales y teatrales, pero, a diferencia del Convenio de Berna, el Tratado de Montevideo disponía de una lista más amplia de derechos patrimoniales exclusivos, ${ }^{84}$ protegía expresamente las obras fotográficas y coreográficas, ${ }^{85}$ y reconocía derechos exclusivos en la traducción de obras análogos a los de cualquier otra obra protegida. ${ }^{86}$

Las razones por las cuales los países americanos no accedieron al Convenio de Berna aún constituyen un misterio para los estudiosos. ${ }^{87}$ Algunos autores ven la reticencia americana a ser parte del Convenio de Berna y la adopción del Tratado de Montevideo como la reafirmación de independencia de los países americanos, el rechazo a la hegemonía europea, y, por sobre todo, la profunda convicción de que ser partes del Convenio de Berna era inconveniente para los países de una región que preferentemente importaban obras protegidas. ${ }^{88}$ Las Américas no tenían razón para ser parte de un acuerdo internacional que deterioraría sus términos comerciales, al incrementar artificialmente el costo de acceso a bienes culturales por ley. Cualquiera sea la razón de la adopción del Tratado de Montevideo, que de hecho fue ratificado sólo por algunos países, ${ }^{89}$ él simboliza el primer esfuerzo de cohesión del continente americano por lograr su propia vía hacia el derecho internacional del derecho de autor. ${ }^{90}$

\footnotetext{
82 Véase cita 22 y 51.

83 UChtenhagen (1998), p. 80. Véase también Singer (1909), p. 143; LAdAs (1938), pp. 654-655; Baires (1897), pp. 147-160.

84 Tratado de Montevideo, artículo 3.

85 Tratado de Montevideo, artículo 5.

${ }^{86}$ Tratado de Montevideo, artículos 3 y 6.

${ }^{87}$ BeLLido (2009), p. 2.

${ }^{88}$ LipszYc (1998a), p. 20. Véase UChtenhagen (1998), pp. 74-81, quien se refiriere a la divergencia de intereses en torno a la impresión entre Europa y América Latina.

${ }^{89}$ Véase UChtenhagen (1998), pp. 92-93, quien sugiere que el Tratado de Montevideo satisfacía esencialmente las necesidades del sector editorial argentino, proveyendo protección de acuerdo a su legislación en su zona de influencia constituida por los países partes del tratado.

${ }^{90}$ Canyes et al. (1950), p. 11; Goldbaum (1954), p. 35. Véase también, Bellido (2011), p. 11, quien sostiene que "the Montevideo Convention [w] as an inaugural Latin American attitude moving towards international copyright.
} 
En este punto es conveniente considerar que, desde finales del siglo XIX y hasta bien entrados en el siglo XX, los países de América Latina continuaban siendo preferentemente países exportadores de materias primas, con economías especializadas en un solo producto y alta concentración de las ventas. ${ }^{91}$ En la década de 1930, todas las economías de la región dependían de sólo un producto -tal como café, bananas, o petróleo-y más del $65 \%$ de sus exportaciones tenía por destino tan solo cuatro países: Estados Unidos, Reino Unido, Francia y Alemania. ${ }^{92}$ La Primera Guerra Mundial, la Gran Depresión y la producción de nuevos productos sintéticos deterioraron progresivamente los términos comerciales de la región y generaron desencanto con el modelo monoexportador de productos hacia el extranjero. ${ }^{93}$ Para superar dichos inconvenientes de dependencia con los mercados internacionales, a mediados del siglo XX, los países de América Latina adoptaron un nuevo modelo de desarrollo: industrialización por sustitución de importaciones. ${ }^{94}$

La nueva política económica promovió el desarrollo de las industrias culturales locales. Son abundantes los ejemplos de dicho proceso. En México, desde mediados de los treinta, tiene lugar la denominada "época de oro" de la cinematografía local, que impulsó el posterior desarrollo del nuevo cine latinoamericano. ${ }^{95}$ Lo propio sucedió en el sector editorial de la región, que experimenta un ostensible incremento productivo a partir de los mismos años, ${ }^{96}$ cimentado en políticas proteccionistas, a las cuales se suma la contribución de editores e intelectuales españoles en éxodo a raíz de la Guerra Civil y la dictadura franquista. ${ }^{97}$ Esto favoreció, especialmente en la América Latina hispanoparlante, el florecimiento del boom literario de los sesenta y setenta. Sin embargo, la actitud prevaleciente en la región aún renegaba de adherir a instrumentos internacionales que perpetuasen una dependencia cultural con Europa, particularmente con España, y, en cambio, se abogaba por soluciones que fortaleciesen la producción e intercambio en la región. ${ }^{98}$

\footnotetext{
91 Bulmer-Thomas (2003), pp. 46-81.

92 Franko (2007), pp. 40-43.

${ }^{93}$ Franko (2007), p. 50. Véase también, Thorp (1984), pp. 57-81; Dean (1984), pp. 719-722; BulMER-THOMAS (2003), pp. 152-231.

${ }^{94}$ Franko (2007), p. 50; SKidmore et al. (2010), pp. 358-360. Véase también, FrrenCH-Davis et al. (1984), pp. 159-249.

95 SILVA (2011), pp. 9-10.

96 Lago (1934), pp. 153-157; Subercaseaux (2010), pp. 133-176.

97 Diego (2010); Martínez (1982), p. 381.

98 LaGo (1934), pp. 159-166.
} 
Entretanto, una serie de sucesivos tratados intentaron perfeccionar el sistema interamericano de derechos de autor, ${ }^{99}$ hasta la adopción de la Convención sobre la Propiedad Literaria de Buenos Aires de 1910. ${ }^{100}$ Ésta requería protección de acuerdo a trato nacional, excepto respecto del plazo de protección, ${ }^{101}$ y simplificó las formalidades necesarias para la obtención de protección de los derechos autorales. ${ }^{102}$ Sin embargo, pese a que la Convención de Buenos Aires logró una amplia adhesión por los países del continente americano, los autores tienden a estar de acuerdo en que careció de eficacia y, consecuentemente, nuevos instrumentos intentaron mejorar el sistema, ${ }^{103}$ aunque carecieron de similar nivel de adhesión, ${ }^{104}$ hasta la adopción de la Convención Interamericana sobre derechos de autor en obras literarias, científicas y artísticas, suscrita en Washington en $1946 .{ }^{105}$

La Convención de Washington consolidó el sistema interamericano de derecho de autor. Ella no sólo garantizó derechos patrimoniales exclusivos a los autores en una amplia categoría de obras, sino que también derechos morales, tales como autoría e integridad sobre la obra. ${ }^{106}$ Ella no derogó las formalidades

99 Convención para la Protección de las Obras Literarias y Artísticas, suscrita en Ciudad de México, el 27 de enero de 1902. O.A.S. T.S. № 32; y Convención sobre Patentes de Invención, Dibujos y Modelos Industriales, Marcas de Fábrica y Comercio, y Propiedad Literaria y Artística, suscrita en Río de Janeiro, el 23 de agosto de 1906. O.A.S. T.S. № 18.

${ }_{100}$ Convención sobre Propiedad Literaria y Artística suscrita en Buenos Aires el 11 de agosto de 1910. O.A.S. T.S. N ${ }^{\circ} 22$ (Convención de Buenos Aires).

101 Convención de Buenos Aires, artículo 6.

102 Convención de Buenos Aires, artículo 3. Véase CANYes et al. (1950), p. 13; LADAS (1938), pp. 661663; LADAS (1940-1941), pp. 291-293.

103 Acuerdo sobre Propiedad Literaria y Artística, suscrito en el Congreso Bolivariano de Caracas, 17 de julio de 1911; y Revisión de la Convención de Buenos Aires sobre la sobre Propiedad Literaria y Artística, suscrita en La Habana el 1 de febrero de 1928. O.A.S. T.S. № 34 (Convención de La Habana). La Convención de la Habana fue el intento más ambicioso en brindar protección a los derechos de autor en el sistema interamericano. Si bien no suprimiría las formalidades del país de origen, garantizaba protección convencional a las obras que incluían un simple aviso de derechos autorales (artículo 3); sugería un término de protección por la vida del autor más 50 años (artículo 6); reconocía el derecho moral de integridad (artículo 13 bis); y actualizaba la normativa a las nuevas tecnologías de la época, esto es, la reproducción mecánica de música y la cinematografía (artículos 2, 4, y 5). La Convención de La Habana tenía por propósito reemplazar a la Convención de Buenos Aires de 1910, pero, en definitiva no tuvo éxito dado que sólo algunos países le ratificaron.

104 Véase LADAS (1938), pp. 648-650, y 654, quien se refiere a la subsistencia de múltiples tratados simultáneos entre determinados países.

105 Convención Interamericana sobre Derechos de Autor en Obras Literarias, Científicas y Artísticas, adoptada en Washington el 22 de junio de 1946. Un Registration: 03/20/89 № Vol. 24373 (Convención de Washington). Véase ReA (1946-1947).

106 Convención de Washington, artículos II, III, IV, y XI. 
del país de origen, pero rechazo éstas a efectos de obtener protección del derecho de autor en otro de los países parte. ${ }^{107}$ Sin embargo, las significativas diferencias entre la legislación interna de los países contratantes impidió lograr acuerdo en el plazo de protección. ${ }^{108}$ La Convención simplificó el sistema interamericano, pues derogó las convenciones previas suscritas entre sus estados contratantes, sin afectar los derechos adquiridos de acuerdo a dichas convenciones. ${ }^{109} \mathrm{La}$ flexibilidad de la Convención de Washington permitió su adhesión por la mayoría de los países de las Américas, los que se abocaron a su implementación en su derecho interno.

Los países americanos se proveyeron de un sistema internacional de derechos autorales más flexible que, por lo mismo, se adecuaba mejor a sus necesidades. A diferencia del Convenio de Berna, el sistema interamericano permitía a los países parte determinar la extensión del plazo de protección de los derechos autorales y admitía la exigencia de formalidades para la obtención de protección conforme al derecho interno, de modo que las obras que no cumplían con dichas formalidades pasaban a engrosar el dominio público, permitiendo su explotación sin autorización ni pagos a los titulares de derechos. ${ }^{110}$ A través del sistema interamericano, los países de la región podían rehuir proteger las obras europeas $y$, de tal modo, obtener acceso a piezas fundamentales para satisfacer algunas de sus necesidades culturales. Esto explica por qué los países latinoamericanos no sólo rechazaron ser partes del Convenio de Berna, sino que también rehusaron la adhesión general de los países europeos al sistema interamericano; como resultado de ello, los países de la región privaron de protección a las obras provenientes de sus antiguos colonizadores. ${ }^{111}$

A mediados del siglo pasado, a pesar de sus diferencias, el derecho de autor en América Latina tenía ciertas características comunes. Al reconocimiento constitucional de los derechos de autor en la mayoría de los países, ${ }^{112}$ se adicionaba la vigencia de leyes específicas en la materia. ${ }^{13}$ Dichas leyes garantizaban derechos exclusivos de carácter patrimonial y morales a los autores

107 Convención de Washington, artículos IX y X. Véase CANYES et al. (1950), pp. 20 y 175; Goldbaum (1954), pp. 78, 168, y 169; ReA (1946-1947), pp. 23-25.

108 Véase Canyes et al. (1950), pp. 19-20; Goldbaum (1954), pp. 162-166.

109 Convención de Washington, artículo XVII. Véase Goldbaum (1954), pp. 201 y ss.

110 Schmitz Vaccaro (2009), pp. 353-355.

111 UChtenhagen (1998), pp. 78-80.

112 Harvey (1993), pp. 15-16, refiriéndose al "constitucionalismo cultural" de América Latina, que considera la inclusión de cláusulas constitucionales en materia de derechos de autor, así como en otras materias culturales, tales como la protección de la diversidad lingüística y los sitios arqueológicos.

113 Véase CANYEs et al. (1950), pp. 161-165. 
sobre una amplia gama de creaciones. Para obtener protección era aun esencial el cumplimiento de ciertas formalidades, tales como la inclusión de un aviso de derechos autorales en las obras, el depósito de cierto número de copias en alguna institución pública y el registro de la obra ante algún órgano público. ${ }^{114}$ La Convención de Washington no derogó las formalidades para obtener protección en el país de origen, pero sí aquéllas requeridas para lograr protección bajo la propia Convención. ${ }^{115}$ De hecho, inclusive Brasil, que fuera el único país de América Latina signatario del Convenio de Berna desde 1922,116 aun requería formalidades en su derecho interno a efectos de brindar protección a las obras. ${ }^{117}$ Otra característica del derecho de autor en la región era la falta de acuerdo entre los países en torno a la extensión del plazo de protección, el cual fluctuaba desde 20 a 80 años post mortem auctoris, con algunos países que incluso brindaban protección a perpetuidad. ${ }^{118}$

La existencia de un régimen de excepciones y limitaciones a los derechos de autor es otra característica común entre los países latinoamericanos. De hecho, la propia Convención de Washington establece algunas limitaciones, tal como aquélla que permite la reproducción de artículos de actualidad en periódicos y revistas, ${ }^{119}$ otra a efectos de cita, ${ }^{120}$ y otra más permitiendo la traducción de breves fragmentos de obras. ${ }^{121}$ La Convención no impedía a los países la adopción de excepciones adicionales y, de hecho, los países adoptaron varias otras en su derecho interno a efectos de satisfacer necesidades de interés público.

En suma, hacia finales de la Segunda Guerra Mundial, existían dos sistemas de protección de los derechos de autor en pugna: el europeo y el interamericano. En términos bastante simples, el sistema de derechos autorales europeo, que estaba abierto a su accesión por otros países, proveía protección automática a los autores por sus vidas más al menos 50 años adicionales, pero no brindaba demasiada flexibilidad para satisfacer necesidades de interés público. El sistema interamericano, que estaba limitado a los países de las Américas, proveía

\footnotetext{
114 CANYes et al. (1950), p. 174.

115 Convención de Washington, artículos IX y X.

116 Bogsch (1986), p. 30.

117 Canyes et al. (1950), pp. 49-50; Mizukami (2007), p. 290.

118 Los plazos de protección, en general, se extendía a la vida del autor más: 20 años en Chile, México, y Perú; 25 años en El Salvador; 30 años en Argentina, Bolivia, República Dominicana, y Venezuela; 40 años en Uruguay; 50 años en Costa Rica and Ecuador; 60 años en Brasil; 80 años en Colombia, Cuba, y Panamá; y a perpetuidad en Guatemala y Nicaragua. Véase Canyes et al. (1950), pp. 173-174.

119 Convención de Washington, artículo VI.

${ }^{120}$ Convención de Washington, artículo XII (1).

121 Convención de Washington, artículo XII (2).
} 
protección internacional, por un período determinado discrecionalmente por los países parte, a favor de los autores que habían cumplido con las formalidades establecidas en el país de origen. Tales diferencias entre ambos sistemas hacía ilusoria toda protección verdaderamente global a los derechos de autor y requería algún esfuerzo significativo para lograr la armonización internacional. De hecho, en 1928 ya había tenido lugar un intento a favor de la convergencia de ambos sistemas, pero éste falló, conduciendo, de un lado, a una nueva simple revisión del Convenio de Berna y, de otro lado, a la Convención de La Habana, la cual no atrajo a muchos países de América Latina. ${ }^{122}$

\section{El ingreso al régimen internacional de derechos de autor}

La necesidad por armonizar la normativa internacional sobre derechos de autor se tornó urgente tras la Segunda Guerra Mundial. Entonces, ya no sólo la resistencia de los países de América Latina y de los Estados Unidos por adherir al Convenio de Berna resultaba problemática, sino que, además, la devastada economía europea y la progresiva pérdida de sus colonias de ultramar incrementaban los riesgos de los titulares de derechos autorales de no ser reconocidos sus derechos en las emergentes naciones resultantes de la descolonización de África y Asia, tales como India, Pakistán y Bangladesh. La fragmentación del poder colonial en varios nuevos estados independientes creaba el peligro de que éstos no accedieran al Convenio de Berna, lo cual urgía a los titulares de derechos a acordar alguna modalidad que permitiese preservar aquella protección de que gozaban durante la era colonial.

El Convenio de Berna provee un mecanismo para hacer frente a la descolonización de territorios por los países firmantes. Se trata de la denominada "cláusula colonial" que garantiza cierta continuidad en la protección de los derechos autorales desde un antiguo a un nuevo estatus jurídico de un territorio determinado, esto es, cuando un país pasa de ser una colonia a un nuevo estado independiente. ${ }^{123}$ Sin embargo, el mecanismo en cuestión no es suficiente, pues requiere aún de la aceptación por la antigua colonia. Por un lado, estos nuevos países en desarrollo estaban reacios a asumir los altos estándares del Convenio de Berna; por el otro lado, Europa necesitaba proteger su potencial mercado alentando la adhesión a dicho Convenio y, al mismo tiempo, evitar que los pocos países en desarrollo que ya eran partes de él lo denunciaran.

122 LADAS (1938), pp. 650-653, y 666-679.

123 Convenio de Berna-Acta de Bruselas de 1948, artículo 27. Hoy, Convenio de Berna para la Protección de las Obras Literarias y Artísticas, revisado en París, 24 de julio de 1971 (Convenio de Berna-Acta de París de 1971), artículo 31. 
Para superar la brecha entre las necesidades de los países en desarrollo y la protección promovida por los europeos, en 1952, bajo los auspicios de la Organización de las Naciones Unidas para la Educación, la Ciencia y la Cultura (UNESCO), se concluyó la Convención Universal sobre Derechos de Autor. ${ }^{124} \mathrm{La}$ Convención intentó brindar una protección global a los autores a través de un instrumento verdaderamente universal que, no obstante, se cuidaba de no afectar los sistemas de protección ya vigentes. ${ }^{125}$ Un país parte podía lograr protección en otros países mediante la concesión de trato nacional y el cumplimiento de ciertos estándares mínimos de protección, incluyendo un plazo más breve que aquél establecido en el Convenio de Berna y un sistema simplificado de formalidades. ${ }^{126}$ La Convención Universal no derogó las formalidades dentro del derecho interno de los estados parte, ${ }^{127}$ pero estableció que la simple noticia de derechos de autor en la obra era condición suficiente para lograr la protección prevista en la misma convención. ${ }^{128}$ Ella garantizaba derechos exclusivos sobre la traducción, pero, al mismo tiempo, establecía un mecanismo flexible de licencias obligatorias para la traducción y reproducción de obras. ${ }^{129}$ Todo ello permitía a la mayoría de los países de América Latina adherir a la Convención Universal y, de tal modo, lograr una protección universal sin necesidad de introducir cambios significativos en su derecho interno. En la práctica, la Convención Universal suministró un puente de un sentido hacia los estándares más altos del Convenio de Berna mediante la adopción de ciertas flexibilidades. ${ }^{130}$

La Convención Universal logró su propósito, al proveer un mecanismo susceptible de proveer protección universal a los autores. En los años sucesivos, los países de las Américas accedieron a la Convención y obtuvieron protección más allá de sus fronteras para sus nacionales, sin necesidad de modificar sus legislaciones internas. Los países parte del Convenio de Berna también accedieron a la Convención Universal; después de todo, obtener una protección menguada para sus autores era mejor que permanecer sin protección alguna.

${ }^{124}$ Convención Universal sobre Derecho de Autor 1952, adoptada en Ginebra, el 6 de septiembre de 1952. UN Registration: 09/27/55 № Vol. 2937 (Convención Universal).

125 Convención Universal, preámbulo.

${ }^{126}$ Convención Universal, artículos I, II, y IV con Convenio de Berna - Acta de París de 1971, artículo 7.

127 Convención Universal, artículo III (2).

128 Convención Universal, artículo III (1).

${ }^{129}$ Convención Universal, artículo V.

130 Véase LiPSZYC (1999), pp. 604-605, y 751; ANTEQuera (1994), p. 572; y Loredo (2000), p. 241. Sin embargo, la Convención Universal no permitía migrar desde el Convenio de Berna hacia la Convención Universal, sancionando a aquellos países que denunciasen el Convenio de Berna. Véase Convención Universal, Declaración anexa relativa al Artículo XVII. 
Para estos países, sin embargo, la Convención Universal era aún una solución insatisfactoria, por su breve plazo de protección, requerimientos de formalidades, y permisivas disposiciones sobre traducción. Además, la Convención Universal no fomentaba la adhesión a los estándares del Convenio de Berna por los nuevos países, ni era una garantía para evitar su denuncia por los pocos países en desarrollo que ya habían accedido a él. Para los países parte del Convenio de Berna, la Convención Universal era antes que un puente una cimbra, una estructura provisional del derecho internacional para avanzar hacia un objetivo más permanente, el cual era la adopción del sistema europeo como estándar universal. En consecuencia, el próximo paso europeo para el derecho internacional de los derechos de autor era claro: hacer converger ambos sistemas en torno al Convenio de Berna.

El Acta de Estocolmo de 1967 del Convenio de Berna fue el primer intento de lograr la antes mencionada convergencia, ${ }^{131}$ mediante la concesión de ciertas flexibilidades, aun cuando preservando un largo plazo de protección automática. El Acta de Estocolmo permitía a los países adoptar excepciones y limitaciones, pero siempre que fuese cumpliendo con la denominada regla de los tres pasos, que exige ellas se circunscriban a determinados casos especiales, no atenten a la explotación normal de la obra, ni causen un perjuicio injustificado a los intereses legítimos del autor. ${ }^{132}$ Otra flexibilidad era la conocida cláusula del "régimen de diez años", ${ }^{133}$ de acuerdo con la cual al acceder un país podría disponer que los derechos exclusivos de traducción expirasen en obras extranjeras, si ellas carecían de traducción en los idiomas de dicho país dentro de los diez años contados desde su primera publicación. Además, un protocolo adicional autorizaba a los países en desarrollo para expedir licencias obligatorias para la traducción de los mismos trabajos en un período más corto. ${ }^{134}$ Pero, a pesar de sus concesiones hacia los países en desarrollo y la accesión de nuevos países, el Acta de Estocolmo no tuvo éxito. Los titulares de derechos instaron a los países desarrollados para evitar la ratificación del Acta de Estocolmo, la que devino

131 Convenio de Berna para la Protección de las Obras Literarias y Artísticas, revisado en Estocolmo, 14 de julio de 1967 (Convenio de Berna-Acta de Estocolmo de 1967). Véase Monsalve (1967), p. 83.

132 Convenio de Berna-Acta de Estocolmo de 1967, artículo 9 (2). Este test sería posteriormente extendido en su ámbito de aplicación a otros derechos distintos del de reproducción y exigiendo que no existiese un perjuicio injustificado a los intereses legítimos del titular de los derechos de autor. Véase Acuerdo sobre los Aspectos de los Derechos de Propiedad Intelectual relacionados con el Comercio (Acuerdo sobre los ADPIC), 15 de abril de 1994, Acuerdo de Marrakech que establece la Organización Mundial de Comercio, Anexo 1C, 1869 U.N.T.S. 299.

133 Convenio de Berna-Acta de Estocolmo de 1967, artículo 30.

134 En general, Véase Mouchet (1969); NdiAye (1986-1987); Ricketson (1987), pp. 590-630; Ricketson y GinSBURG (2006), pp. 881-924. 
un fracaso; ${ }^{135}$ de hecho, el proceso que conduciría a una nueva revisión del Convenio de Berna comenzó casi inmediatamente.

El segundo intento por hacer converger el derecho internacional del derecho de autor tuvo lugar en conferencias sucesivas celebradas en París en 1971, en las cuales se revisó ambos, el Convenio de Berna y la Convención Universal. ${ }^{136}$ A pesar de sus diferencias filosóficas, las conferencias adoptaron casi idénticas modificaciones en las flexibilidades provistas por la Convención Universal y aquellas incluidas en el Apéndice del Convenio de Berna, a través del Acta de París de 1971. ${ }^{137}$ Esto es, ambos instrumentos internacionales contemplan un mismo mecanismo que permite a los países en desarrollo expedir licencias obligatorias para la traducción y/o reproducción de obras publicadas. ${ }^{138}$ Además, el Convenio de Berna permitió adoptar excepciones a los derechos autorales en el derecho interno de los estados parte, siempre con sujeción a la regla de los tres pasos. ${ }^{139}$ También conservó la cláusula del "régimen de diez años" que permite el cese del derecho exclusivo de traducción, pero sólo respecto de nuevos países adherentes al Convenio. ${ }^{140}$ Los nuevos instrumentos no lograron otra convergencia, pero al menos neutralizaron el riesgo que las versiones previas representaban para los titulares de derechos, al limitar ciertas flexibilidades e introducir un burocrático y complejo régimen de licencias obligatorias para los países en desarrollo, el que, a la postre, demostraría ser completamente inútil para satisfacer sus necesidades. ${ }^{141}$

Hacia entonces, entre las décadas de los cincuenta y los ochenta, los países de América Latina, la mayor parte de los cuales estaban bajo alguna forma de régimen autoritario, ${ }^{142}$ implementaron un modelo de desarrollo económico basado en la sustitución de importaciones con producción doméstica mediante el reforzamiento de su industrialización. Este modelo requería de un activo rol del estado en la economía, incluyendo al estado como empresario, como apoyo financiero del sector privado, y la adopción de medidas proteccionistas,

\footnotetext{
135 Drahos y Braithwaite (2002), p. 77; Hemmungs (2010), p. 547.

136 Confróntese Olian (1974), p. 109.

137 ULMER (1971), p. 347.

138 Confróntese Convenio de Berna-Acta de París de 1971, Anexo: Disposiciones especiales relativas a países en desarrollo, con Convención Universal sobre Derechos de Autor revisada el 24 de julio de 1971, artículos V-V quarter.

139 Convenio de Berna-Acta de París de 1971, artículo 9 (2).

140 Convenio de Berna-Acta de París de 1971, artículo 30 (2) (b).

141 CERDA (2012).

142 Véase Skidmore et al. (2010), pp. 379-386; KeEn y Haynes (2004), pp. 270-274.
} 
tales como elevados aranceles y restricciones comerciales; el modelo no rechazaba la operación de corporaciones transnacionales, en tanto contribuyesen a la economía doméstica. ${ }^{143}$ Los logros de este modelo de desarrollo fueron desiguales a través de la región, ${ }^{144}$ pero debe destacarse que los tres principales países productores de libros en América Latina adhirieron al acuerdo europeo de derechos autorales, el Convenio de Berna, por aquella época: Brasil había accedido ya en 1922, sacando partido de sus ventajas competitivas en el mercado de habla portuguesa; en 1967, Argentina y México accedieron también. Es de suponer que el sector editorial de estos países sacó ventajas del proteccionismo del modelo de industrialización mediante sustitución de importaciones, tales como fuertes subsidios, importantes compras públicas y algunos beneficios legales.

Las revisiones del Convenio de Berna no tuvieron éxito en América Latina, sin embargo, como lo prueba el hecho de que sólo unos pocos países accedieron a ellas, y aun éstos fallaron en su implementación en derecho interno. Hacia los ochenta, a Argentina, Brasil y México se habían sumado Chile (1970) y Costa Rica (1978). En consecuencia, para la mayoría de los países de la región, los instrumentos principales en materia de derecho internacional del derecho de autor continuaban siendo la Convención de Washington y la Convención Universal de 1952. Más aún, como se ha mencionado, el acceso al Convenio de Berna no garantizaba que los países parte efectivamente la implementasen en su derecho interno; ${ }^{145}$ por ejemplo, Brasil aún conservaba una protección basada en la exigencia de ciertas formalidades hacia los sesenta. ${ }^{146}$ Del mismo modo, Argentina requería el registro de la obra para la protección de las traducciones. ${ }^{147}$ Todavía peor, algunos de los países parte habían adoptado normas de derecho interno que infringían flagrantemente las obligaciones del Convenio de Berna; por ejemplo, la ley de propiedad intelectual adoptada por Chile en 1970 redujo el plazo de protección de 50 a 30 años post mortis auctoris. ${ }^{148}$ México también proveía sólo 30 años adicionales de protección tras la muerte del creador. ${ }^{149}$ Esto demuestra que el Convenio de Berna presenta tres serias limitantes: un reducido número de accesiones,

143 FRANKO (2007), pp. 61-68.

144 Franko (2007), pp. 68-72; SKIDMORE et al. (2010), pp. 361-362.

145 Convenio de Berna-Acta de París de 1971, artículo 36.

146 Pan American Union (1962), pp. 21-23. Véase al respecto, cita 119.

147 Organization of American States-General Secretariat (1984a), p. 19.

148 Véase Ruiz (2008).

149 Organization of American States - General Secretariat (1984b), p. 13. 
la necesidad de disponer de legislación de implementación y la ausencia de mecanismos de observancia.

Hacia la década de los setenta, con la mayor parte de América Latina bajo regímenes dictatoriales alimentados por la Guerra Fría, ${ }^{150}$ el modelo de desarrollo económico basado en la sustitución de importaciones devino insustentable, a pesar de algunos intentos por prolongarle mediante la extensión de los mercados locales por medio de iniciativas de integración regional y la inyección de recursos financieros a través de deuda externa. Ello condujo a la más severa crisis económica que golpeó a la región a comienzos de la década de los ochenta, cuando varios países declararon su moratoria a los mercados financieros internacionales. Durante ese período, que llegaría ser conocido como "la década pérdida" en América Latina, los países de la región lidiaron simultáneamente con la inestabilidad económica, la renegociación financiera de la deuda extranjera, la transición hacia incipientes gobiernos democráticos y un creciente descontento social ocasionado por altas tasas de desempleo e inflación resultante de las políticas de reajuste. Tras lograr cierta estabilidad macroeconómica, a través de los noventa, América Latina se embarcó en dos procesos paralelos: la reestructuración económica y la redemocratización política.

Los países de América Latina, desde la década de los noventa, giraron desde su previo modelo de desarrollo hacia dentro hacia un modelo de liberalización comercial. ${ }^{151}$ Siguiendo las fuertes recomendaciones de las instituciones financieras internacionales, los países implementaron una serie de políticas basadas en el mercado conocidas como el Consenso de Washington. ${ }^{152}$ Estas políticas incluían la liberalización financiera y comercial unilateral, la privatización de la economía, desregulación de los mercados, control fiscal, reducción de impuestos, aranceles y gasto social, entre otras. Sobre la premisa de que la débil observancia contractual desalentaba la inversión en la región, asegurar la protección de los derechos de propiedad se transformó en parte de la solución del Consenso de Washington. De tal manera, los derechos de propiedad intelectual alcanzaron el estatus de un componente esencial del desarrollo económico. ${ }^{153}$ Si bien el nivel de implementación y resultados obtenidos con la nueva política variaron de un país a otro, hacia el final del siglo pasado, todos los países de la región tenían ya normas de derecho interno sobre derechos de autor en línea con la normativa internacional.

${ }^{150}$ Véase Rouquie (1984), pp. 247-270. Véase también, MeAde (2010), pp. 214-233.

151 Franko (2007), pp. 154-178.

152 SKIDMORE et al. (2010), pp. 368-370.

153 MiROw (2004), p. 211. 
Desde los ochenta, como se ha mencionado, América Latina ha progresado continuamente en su redemocratización. ${ }^{154}$ Conceptualizar qué es una democracia es una tarea ardua con amplio debate entre los expertos y que excede los propósitos de este artículo, pero sí es posible apuntar varias características de la región que corroboran dicho progreso. La casi totalidad de los países de la región tiene gobiernos democráticamente electos con voto universal en un sistema multipartidista. ${ }^{155}$ El históricamente huidizo estado de derecho se ha impuesto a través de la región, aunque en diferentes niveles. Por ejemplo, adicionalmente a las mejoras a la administración de justicia e independencia del poder judicial, en varios países nuevas instituciones han reforzado las obligaciones democráticas, tales como defensores del pueblo, órganos independientes de persecución penal y cortes constitucionales. ${ }^{156} \mathrm{El}$ reconocimiento y exigencia de los derechos humanos ha recibido mejoras ostensibles, tanto en el derecho interno de los países de la región, como a través del sistema interamericano de derechos humanos. ${ }^{157}$ Por supuesto, aún existe un amplio margen de maniobra para perfeccionamiento en diversas áreas, tales como transparencia pública, participación ciudadana, lucha contra la corrupción, la guerrilla y el tráfico de drogas.

Simultáneamente, mientras América Latina avanzaba en la estabilización económica y redemocratización política, desde finales de los ochenta y durante los noventa, la agenda internacional en materia de derechos de autor experimentó un nuevo proceso de revigorización. Por un lado, el fin de la Guerra Fría y la creciente globalización de la economía acentuaron la importancia de lograr la armonización internacional de la propiedad intelectual. Por otro lado, los desafíos y oportunidades que ofrecían las nuevas tecnologías digitales hacían necesario, al menos, una cierta actualización del sistema de derechos autorales. En el caso de los países de América Latina, era el momento de introducir mejoras en los sistemas jurídicos y volver a comprometerse con los foros internacionales. Al mismo tiempo, como hemos mencionado, América Latina abandonó el proteccionismo y la sustitución de importaciones como modelo de política comercial y económica de desarrollo;; ${ }^{158}$ en cambio, los países de la región abrazaron la liberalización y privatización de sus economías, e intentaron

\footnotetext{
154 Véase Rouquie (1984), pp. 279-300. Véase también SKIDMORE et al. (2010), pp. 389-391.

155 Véase Hagopian y Mainwaring (2005), p. 3. Véase también Skidmore et al. (2010), p. 390.

156 Véase Carpio (2005), pp. 972-985; Uprimny (2011), pp. 1593-1594; Gargarella (2013), pp. $148-195$. Véase también BreWER-CARIAS (2009).

157 Véase Aвramovich (2009).

158 Huerta Casado (1998), pp. 126-128.
} 
por diversos medios acceder a los mercados extranjeros. ${ }^{159}$ En este contexto, la propiedad intelectual y los derechos de autor se transformaron en parte esencial del paquete de medidas de comercio internacional adoptado por América Latina. Sin embargo, los autores están de acuerdo con que el ímpetu por incluir propiedad intelectual era, y aún continúa siendo, más externo que interno. ${ }^{160}$

Los cambios en la política y la normativa sobre derechos de autor estadounidenses ejercieron también influencia en la región. En 1988, Estados Unidos accedió al Convenio de Berna, ${ }^{161}$ tras adecuar su legislación interna a las exigencias de éste, principalmente mediante la concesión de protección automática, si bien omitiendo el tratamiento de los derechos morales. ${ }^{162}$ Además, Estados Unidos incorporó los estándares del Convenio de Berna en su política de comercio internacional, especialmente a través del Reporte Especial 301 que presiona con la denegación de preferencias arancelarias a aquellos países que no proveen protección adecuada y efectiva a los derechos de propiedad intelectual, o deniegan un justo y equitativo acceso al mercado a estadounidenses que dependen de los derechos de propiedad intelectual. ${ }^{163}$ A nivel internacional, se produce la transición de la discusión sobre derechos de autor desde la agencia especializada de Naciones Unidas, la Organización Mundial de la Propiedad Intelectual, hacia un foro comercial, la Organización Mundial de Comercio (OMC), un escenario que favoreció la agenda de los países desarrollados respecto de aquellos en desarrollo, como abundante literatura se ha encargado de documentar. ${ }^{164}$ En concreto, Estados Unidos formuló una propuesta para incluir propiedad intelectual ante la OMC, la cual incluía los estándares de protección autoral alentados por el Convenio de Berna, así como requerimientos adicionales en relación a la protección de bases de datos y programas computacionales. Después de 102 años evitando al Convenio de Berna y 99 sacando ventajas de las flexibilidades del sistema interamericano

\footnotetext{
159 Stiglitz (2003), pp. 53 y ss.

160 Huerta (1998), pp. 126-133.

161 Berne Notification N ${ }^{\mathbf{0}}$ 121: Accession by the United States of America, 17 de noviembre de 1988.

162 Berne Convention Implementation Act of 1988. Véase Pub. L. № 100-568 (Oct. 31, 1988), 102 Stat. 2853.

163 El Reporte Especial 301 es emitido desde 1989, el año siguiente a la accesión de los Estados Unidos al Convenio de Berna, y constituye una revisión del nivel de cumplimiento de los países con ciertos estándares de propiedad intelectual determinados por la Oficina del Representante de Comercio de los Estados Unidos a efectos de instar a encías arancelarias la protección y observancia de las normas sobre la materia, bajo riesgo de privar a los países infractores de ciertas preferencias arancelarias.

164 Véase, en general, Correa (2000); Drahos y Braithwaite (2002); Sell (2003); Abbott et al. (2007).
} 
de derechos de autor, ${ }^{165}$ Estados Unidos se había transformado en el principal campeón de los estándares de Berna ejerciendo presión en otros países para que los adoptasen también, ${ }^{166}$ y así varios países de América Latina adhirieron a ellos, inclusive antes de adoptarse el Acuerdo sobre los ADPIC. ${ }^{167}$

En paralelo a la discusión de nuevas reglas sobre propiedad intelectual en la OMC, algunos países de la región acordaron normas sobre protección de los derechos autorales más fuertes en el marco de negociaciones de acuerdos de integración económica subregional. Este fue el caso del Tratado de Libre Comercio de América del Norte (TLCAN) ${ }^{168}$ y la Decisión 351 de la Comunidad Andina. ${ }^{169}$ El TLCAN creó un área de libre comercio entre Canadá, los Estados Unidos y México, para lo cual requería cierta armonización normativa, incluyendo temas atingentes a propiedad intelectual. Por su parte, aun cuando la Comunidad Andina existía desde 1969, ${ }^{170}$ al iniciarse la década de los noventa se revitalizó y adoptó normativa común uniforme en diversas áreas, tales como inversión extranjera, empresas comunitarias y propiedad intelectual, entre otras. ${ }^{171}$ Para entonces, la Comunidad Andina incluía a Bolivia, Colombia, Ecuador, Perú y Venezuela.

EITLCAN y la Decisión 351 incrementaron significativamente la protección de los derechos autorales entre los países negociadores. No sólo extendieron la protección sustantiva más allá de lo previsto en el Convenio de Berna, sino que además introdujeron restricciones sobre algunas de las flexibilidades

165 Ginsburg y Kernochan (1988-1989). Sin embargo, los editores estadounidenses disfrutaron de la protección del Convenio de Berna sacando ventaja de la disposición del mismo que brinda protección a obras publicadas simultáneamente en otro país que si es parte del Convenio, en este caso usualmente Canadá. Véase Brown (1936), pp. 77-78; BOWKer (1912), p. 339. Véase también KUPFERMAN (1958-1959), pp. 227-231.

166 Este fue sucesivamente el caso de Colombia y Perú (1988), Honduras (1990), Ecuador (1991), Paraguay (1992), Bolivia (1993), y El Salvador (1994).

167 Acuerdo sobre los ADPIC. Al respecto ver nota 134.

168 Tratado de Libre Comercio de América del Norte entre el Gobierno de los Estados Unidos de América, el Gobierno de Canadá y el Gobierno de los Estados Unidos Mexicanos, 17 de diciembre de 1992, 32 I.L.M. 605 (TLCAN).

${ }^{169}$ Comunidad Andina, Decisión № 351 Régimen Común sobre Derecho de Autor y Derechos Conexos, adoptada por la Comisión del Acuerdo de Cartagena, el 17 de diciembre de 1993, Gaceta Oficial de la Comunidad Andina No. 145, 21 de diciembre de 1993 (Decisión 351). Véase AnTEQuera (1995); y PACÓN (2003), pp. 299-324.

170 Acuerdo de Cartagena, Bogotá, de 28 de mayo de 1969, enmendado por el Protocolo de Trujillo, de 10 de marzo de 1996. La Comunidad Andina estuvo originalmente constituida por Bolivia, Colombia, Chile, Ecuador y Perú. En 1973, Venezuela adhirió a la Comunidad. En 1976, Chile la abandonó, e igual hizo Venezuela el 2006.

171 Véase O’KeEre (1996), pp. 818 y ss. 
disponibles en el derecho internacional así como en el derecho interno de los países partes. Por ejemplo, el TLCAN extendió la protección de los derechos de autor a las bases de datos y los programas computacionales, ${ }^{172}$ garantizó derechos exclusivos sobre el arriendo de estos últimos, ${ }^{173}$ e incrementó los requisitos necesarios para extender licencias obligatorias de acuerdo a lo previsto en el Apéndice del Convenio de Berna. ${ }^{174}$ La Decisión 351, por su parte, adoptó un amplio trato nacional mediante la concesión de derechos de autor a todo creador, incluso si su país de origen no confería similar protección a los creadores de los países parte de la Decisión; ${ }^{175}$ ésta también concedió a los titulares derechos exclusivos sobre el arrendamiento, préstamo, e importación de las obras; ${ }^{176}$ y, proveyó protección autoral a los programas computacionales y bases de datos, ${ }^{177}$ entre otros. ${ }^{178}$

EITLCAN y la Decisión 351 también introdujeron mejoras en la observancia internacional de los derechos de autor. EI TLCAN lo hizo mediante la inclusión de un mecanismo de resolución de controversias, ${ }^{179}$ mientras la Comunidad Andina otorgó jurisdicción a un tribunal regional, ${ }^{180}$ el cual, de hecho, ha expedido varias decisiones sobre la materia. ${ }^{181}$ Adicionalmente, la Decisión 351 resolvió otra limitación de las normas de derecho internacional sobre derechos de autor, al hacer innecesaria su implementación en el derecho interno de los países de la Comunidad; la Decisión es normativa comunitaria (esto es, aplicable dentro de la Comunidad Andina), supranacional y autoejecutable, con efectos directos e inmediatos sobre las autoridades comunitarias y domésticas. ${ }^{182}$ Con todo, la normativa comunitaria puede ser complementada por normas de derecho interno, siempre que este último no sea inconsistente con el régimen común. Como resultado de todo ello, el TLCAN y la Comunidad Andina facilitaron

172 TLCAN, artículo 1705 (1).

173 TLCAN, artículo 1705 (2).

174 TLCAN, artículo 1705 (6).

175 Decisión 351, artículo 2.

176 Decisión 351, artículo 13.

177 Decisión 351, artículos 23-27.

178 Decisión 351, artículo 60. Véase Cerda (2012).

179 Véase TLCAN, Capítulo XX: Disposiciones Institucionales y Procedimientos para la Solución de Controversias.

180 Véase Protocolo de Modificación del Tratado de Creación del Tribunal de Justicia de la Comunidad Andina, suscrito en Cochabamba el 28 de mayo de 1996.

181 Véase Helfer y Alter (2008-2009); Helfer et al. (2009).

182 TremoladA (2006); y Rondón (1995), pp. 86-87. 
tanto la accesión como la implementación del Acuerdo sobre los ADPIC por sus países parte. ${ }^{183}$

La conclusión del Acuerdo sobre los ADPIC puso término a la resistencia de los últimos países de América Latina en acceder a los estándares del Convenio de Berna. ${ }^{184}$ El Acuerdo reafirma el Convenio de Berna y hace de éste un instrumento verdaderamente universal para la protección del derecho de autor; cualesquiera sean las razones por las cuales estos países adhirieron a la Organización Mundial de Comercio, ${ }^{185}$ lo más probable es que haya sido por obtener acceso a mercados para sus productos agrícolas, tales países se obligaron a cumplir con el Convenio de Berna, salvo en cuanto a los derechos morales. ${ }^{186}$ El Acuerdo sobre los ADPIC extendió la protección autoral mediante la adopción de nuevas obligaciones sustantivas. ${ }^{187}$ Él también mejoró la observancia de los derechos de propiedad intelectual, por un lado, mediante el establecimiento de específicas obligaciones relativas al cumplimiento forzado de las normas de propiedad intelectual en el derecho interno de los países parte, ${ }^{188}$ y, por otro lado, estableciendo un arreglo institucional que monitorea el cumplimiento de las obligaciones y un sistema de resolución de controversias. ${ }^{189}$ Incluso si el Acuerdo sobre los ADPIC no es autoejecutable, ${ }^{190}$ este exige su implementación en derecho interno dentro de determinados plazos cuya extensión depende del

183 Véase Gómez Velasco (2003), p. 17; Rodríguez Ruiz (2007), pp. 48-49; Huerta Casado (1998), p. 138. Véase también Cristiani (1997), p. 67; Kennedy (2004), pp. 6-7. Confróntese BeCERRA (2004), pp. 35-36, quien sostiene que los estándares impuestos por el TLCAN son, de hecho, más altos que aquellos establecidos por el Acuerdo sobre los ADPIC, en trato nacional, períodos de transición, licencias obligatorias, contratos sobre derechos autorales, y biotecnología, entre otros aspectos.

184 Tras acceder a la Organización Mundial de Comercio y, consecuentemente, al Acuerdo sobre los ADPIC, accedieron también al Convenio de Berna los siguientes países de América Latina: Haití y Panamá (1996), Cuba, República Dominicana, y Guatemala (1997), y Nicaragua (2000).

185 Véase Yu (2006).

186 Acuerdo sobre los ADPIC, artículo 9.

187 Acuerdo sobre los ADPIC, artículos 10 (brinda protección autoral a programas computacionales y bases de datos), 11 (confiere derechos exclusivos de alquiler sobre programas computacionales y obras cinematográficas), 12 (adopta un plazo de protección de al menos la vida del autor más 50 años tras su muerte, o desde la publicación de la obra en ciertos casos), y 13 (adopta la regla de tres pasos modificada como estándar para excepciones y limitaciones a los derechos autorales).

188 Acuerdo sobre los ADPIC, artículos 41-62.

189 Acuerdo sobre los ADPIC, artículos 63, 64, y 68.

190 Si un tratado es autoejecutable o no depende esencialmente de disposiciones de derecho interno de los países parte de dicho tratado, especialmente de su constitución. El Acuerdo sobre los ADPIC reconoce tal circunstancia y la libertad de los países para determinar la manera de implementación del acuerdo a su respectivo sistema y prácticas legales. Véase UNCTAD y ICTSD (2005), pp. 17 y ss.; Correa (2005), pp. 434-435; Gervais (2008), pp. 164-165. 
nivel de desarrollo de cada país. ${ }^{191}$ En el caso de los países de América Latina, ciertos tratados internacionales son autoejecutables, pero esta es una característica de que gozan aquellos instrumentos relativos a derechos humanos y, por consiguiente, otros instrumentos -tales como aquellos relativos a propiedad intelectual o comercio internacional- carecen, lo cual obliga a disponer de normas de implementación en el derecho interno.

El Acuerdo sobre los ADPIC no aborda todos los aspectos atingentes a las nuevas tecnologías digitales. De hecho tan pronto fue concluido, otros dos instrumentos internacionales fueron adoptados ante la Organización Mundial de la Propiedad Intelectual (OMPI), conocidos como los Tratados Internet de la OMPI, ${ }^{192}$ los cuales intentan actualizar las normas sobre derechos de autor y conexos para responder a los desafíos de las mencionadas tecnologías. Varias de las disposiciones de dichos tratados reiteran aquellas establecidas ya en el Convenio de Berna y en el Acuerdo sobre los ADPIC, pero otras resultan más innovadoras en el derecho internacional del derecho de autor, tales como aqueIlas que requieren la protección de las medidas tecnológicas y de la información sobre gestión de derechos, ${ }^{193}$ así como las que reconocen derechos exclusivos en la puesta a disposición en línea de las obras. ${ }^{194}$ Los Tratados Internet de la OMPI adolecen, sin embargo, de limitaciones similares a las del Convenio de Berna: por un lado, carecen de un mecanismo de observancia, dejando la implementación y efectiva observancia de sus disposiciones libradas a la buena fe de los países parte; y, por otra parte, a pesar de su denominación, ellos regulan más bien las tecnologías digitales antes que el entorno en línea, de hecho, ninguno de ellos dispone de reglas específicas acerca de la observancia del derecho de autor en Internet, una materia que también queda librada al derecho interno de los países parte. En el caso de América Latina, la mayoría de los países ha ratificado ambos Tratados Internet de la OMPI y, consecuentemente, los ha implementado o se ha obligado a hacerlo, ${ }^{195}$ una materia cuyo análisis excede los propósitos de este artículo.

En síntesis, la narrativa general nos dice que, durante las últimas tres décadas, el derecho de autor en América Latina ha estado sujeto a un período de

\footnotetext{
191 Acuerdo sobre los ADPIC, artículos 65 y 66.

192 Tratado de la Organización Mundial de la Propiedad Intelectual sobre Derecho de Autor, adoptado en Ginebra el 20 de diciembre de 1996; y Tratado de la Organización Mundial de la Propiedad Intelectual sobre Interpretación o Ejecución y Fonogramas, adoptado en Ginebra el 20 de diciembre de 1996.

193 Tratado de la OMPI sobre Derecho de Autor, artículos 11 y 12.

194 Tratado de la OMPI sobre Derecho de Autor, artículo 8.

195 A abril de 2014, la mayor parte de los países de América Latina han accedido a ambos Tratados Internet de la OMPI, salvo Bolivia, Brasil, Cuba, Haití y Venezuela.
} 
intensa transición. Hacia finales de la década de los ochenta, la mayoría de los países de la región basaban su protección autoral en el sistema interamericano de derecho de autor. Desde entonces, los países de la región han progresivamente adherido al sistema europeo, que se basa en el Convenio de Berna y sus revisiones ulteriores. Durante la década de los noventa, los países se obligaron a estándares aún más altos a través de acuerdos comerciales subregionales con multilaterales, tales como el Acuerdo sobre los ADPIC, la Decisión 351 de la Comunidad Andina, y el Tratado de Libre Comercio de América del Norte. Por último, con contadas excepciones, los países de América Latina han adherido también a ambos Tratados Internet de la OMPI, que establecen innovadoras obligaciones relativas a la protección del derecho de autor y conexos en relación con las tecnologías digitales. Dado que ninguno de los instrumentos internacionales recién mencionados es autoejecutable, excepto la Decisión 351, la efectiva aplicación de sus disposiciones en la región está sujeta a la implementación de sus normas en el derecho interno de los países parte. No obstante, dichos procesos de implementación, así como nuevos compromisos internacionales en materia de derecho de autor asumidos recientemente por países de la región a través de acuerdos bilaterales de comercio, no son objeto de este artículo, sino de un trabajo posterior.

\section{Conclusiones}

La ausencia de estudios sobre la historia del derecho de autor en América Latina ha cimentado diferentes malentendidos en cuanto a su evolución, desde quienes presuponen una cierta uniformidad en la tradición de los derechos autorales y niegan las peculiaridades de la región, hasta quienes suponen que los países latinoamericanos sólo se han preocupado del derecho de autor desde muy recientemente. Este artículo ha confrontado dichos malentendidos, brindando una visión panorámica sobre la evolución del derecho de autor en América Latina.

Los países de América Latina tienen una larga tradición en la protección del derecho de autor. Tan pronto consolidaron su independencia, y tras un breve período de subsistencia de la regulación colonial en la materia, dichos países reconocieron el derecho de autor constitucionalmente y se dotaron a sí mismos de legislación especial que, a pesar de la carencia de significativas capacidades de producción, brindaban protección a los creadores locales.

Las limitaciones inherentes a la legislación local impulsó a los países de las Américas a concebir un sistema de protección del derecho de autor más allá de sus respectivas fronteras. En vez de adherir al Convenio de Berna, lo que habría supuesto brindar protección a las obras producidas en Europa, mellando aún más los ya desfavorables términos de intercambio comercial con 
el Viejo Continente, los países de las Américas emprendieron la construcción del sistema interamericano de protección al derecho de autor, comenzando por el Tratado de Montevideo de 1889 y una serie de instrumentos internacionales subsecuentes.

El sistema interamericano de derecho de autor brindó mayor flexibilidad a los países de la región para lograr protección de sus creadores más allá de sus fronteras, entre los países de las Américas. De hecho, este fue el sistema neurálgico de la protección para los creadores de la región hasta finales de la década de los ochenta, cuando los países latinoamericanos accedieron a ser partes del Convenio de Berna y demás instrumentos subsecuentes en materia de derecho de autor.

Esta breve reseña demuestra no sólo que América Latina dispone de una larga tradición en la protección del derecho de autor, sino también una clara noción de la importancia de obtener su protección más allá de las fronteras de cada país. Si los países de la región accedieron más tardíamente al Convenio de Berna, no se debe a carecer de una tradición o empecinarse en un aislamiento jurídico, sino que al simple hecho de resultarle inconveniente en términos relativos, dado el histórico desbalance de su intercambio comercial sobre obras susceptibles de protección autoral.

\section{Bibliografía CitADA}

Аввотт, Frederick et al. (2007): International Intellectual Property in An Integrated World Economy (Aspen Publishers).

AвRAMOVICH, Víctor (2009): "From Massive Violations to Structural Patterns:

New Approaches and Classic Tensions in the Inter-American Human Rights System", en: SUR-International Journal of Human Rights (vol. 6, № 11), pp. 6-39.

Alcover, Antonio Miguel (1912): Los libros de producción latino-americana (La Habana, Siglo XX).

Ansorena, Luis de (1894): Tratado de la Propiedad Intelectual en España (Madrid, Sáenz de Jubera Hermanos).

ANTEQuera, Ricardo (1977): Consideraciones sobre el Derecho de Autor: Especial referencia a la legislación venezolana (Buenos Aires, s.e.).

— (1994): El nuevo Derecho de Autor en Venezuela (Caracas, Autoralex). (1995): "Copyright and Andean Community Law", en: Revue Internationale du Droit d'Auteur (vol. 166), pp. 56-127.

BAIRES, Carlos (1897): La propiedad literaria y artística en la República argentina (Buenos Aires, Imprenta de Juan Alsina). 
Balázs, Bodó (2011): "Coda: A Short History of Book Piracy", en: Karaganis, Joe (ed.), Media Piracy in Emerging Economies (Nueva York, Social Science Research Council).

BeCERRA, Manuel (2004): La propiedad intelectual en transformación (México, UNAM).

BeLLIDO, José (2009): "Latin American and Spanish Copyright Bilateral Agreements (1880-1904)", en: The Journal of World Intellectual Property (vol. 12), pp. 1-39.

BelLido, José (2011): "Montevideo vs Berne: The Rise of an Interpretation in International Copyright (1888-1898)", en: Revue Internationale du Droit d'Auteur (vol. 229), pp. 5-155.

Bello, Andrés (1932): Obras completas (Santiago de Chile, Ed. Nascimento), tomo 7.

BethelL, Leslie (1984a):"A Note on Literature and Intellectual Life in Colonial Brazil", en: BetHeLl, Leslie (ed.), The Cambridge History of Latin America (Reino Unido, Cambridge University Press), tomo 2.

- (1984b): "The Independence of Brazil", en: Bethell, Leslie (ed.), The Cambridge History of Latin America (Reino Unido, Cambridge University Press), tomo 3.

Bogsch, Arpad (1986): The First Hundred Years of the Berne Convention for the Protection of Literary and Artistic Works (Ginebra, WIPO).

Bowker, Richard Rogers (1912): Copyright: Its History and its Law Being a Summary of the Principles and Practice of Copyright with Special Reference to the American Code of 1909 and the British Act of 1911 (Boston, Houghton Mifflin).

Brading, D. A. (1984): "Bourbon Spain and Its American Empire", en: Bethell, Leslie (ed.), The Cambridge History of Latin America (Reino Unido, Cambridge University Press), tomo 1.

Brewer-Carias, Allan R. (2009): Constitutional Protection of Human Rights in Latin America: A Comparative Study of Amparo Proceedings (Nueva York, Cambridge University Press).

Brown, James L. (1936): Industrial Property Protection throughout the World (Washington, U.S. Government Printing Office).

Bulmer-Thomas, Victor (2003): The Economic History of Latin America since Independence, $2^{\text {a }}$ edición (Nueva York, Cambridge University Press).

BusCaglia, Edgardo y Long, Clarisa (1997): U.S. Foreign Policy and Intellectual Property Rights in Latin America (s.I.i., Hoover Institution-Stanford University). 
CAnyes, Manuel et al. (1950): Copyright Protection in the Americas under National Legislation and Inter-American Treaties, $2^{\text {a }}$ edición (Washington, Pan American Union - Division of Legal Affairs, Dept. of International Law and Organization).

CARPIO, Jorge (2005): "Derecho Constitucional Latinoamericano y Comparado", en: Boletín Mexicano de Derecho Comparado (vol. 114), pp. 949-989.

Cerda, Alberto (2012a): "Copyright Convergence in the Andean Community of Nations", en: Texas Intellectual Property Law Journal (vol. 20), pp. 429-470.

— (2012b): "Derechos de Autor y Desarrollo: Más Allá de la llusoria Solución Provista en el Anexo del Convenio de Berna", en: Revista de Derecho de la Pontificia Universidad Católica de Valparaíso (vol. 38 Nº 1), pp. 181-238.

Clark, Aubert J. (1973): The Movement for International Copyright in Nineteenth Century America (Wesport Connecticut, Greenwood Press).

Clayton, Lawrence A. y Conniff, Michael L. (2005): A History of Modern Latin America, $2^{a}$ edición (s.l.i., Thomson-Wadsworth).

Correa, Carlos M. (2000): Intellectual Property Rights, the WTO and Developing Countries: The TRIPS Agreement and Policy Options (Zed Books).

(2005): "The TRIPS Agreement and Developing Countries", en: MACRORY et al. (eds.), The World Trade Organization: Legal, Economic and Political Analysis (Nueva York, Springer), tomo 2.

Cristiani, Julio Javier (1997): "Las Principales Disposiciones en Materia de Propiedad Intelectual en el Tratado de Libre Comercio de América del Norte y su Repercusión en la Legislación Interna Mexicana", en: Temas Varios tomos (México, Themis), tomo 1.

Chasteen, John Charles (2000): "Cautionary Tale: A Radical Priest, Nativist Agitation, and the Origin of Brazilian Civil Wars", en: Earle, Rebecca (ed.), Rumors of War: Civil Conflict in Nineteenth Century Latin America (Londres, Institute of Latin American Studies).

DANVILA Y CollADO,Manuel (1882): La propiedad intelectual: legislación española y extranjera (Madrid, Imprenta de la Correspondencia).

Dean, Warren (1984): “The Brazilian Economy: 1870-1930", en: Bethell, Leslie (ed.), The Cambridge History of Latin America (Reino Unido, Cambridge University Press), tomo 1.

DieGO, José Luis de (2010): "Algunas notas sobre la edición en América latina", en: IX Congreso Argentino de Hispanistas: El hispanismo ante el Bicentenario (La Plata, 27-30 de abril de 2010). 
Drahos, Peter y Braithwaite, John (2002): Information Feudalism: Who Owns the Knowledge Economy? (Londres, Earthscan).

Enríquez Fuentes, Elena (2008): El comercio de libros entre España y América Latina: Disonancia en la reciprocidad (s.I.i., Alianza Internacional de Editores Independientes).

FariÑas Díaz, José Rafael (2009): "La protección constitucional de la propiedad intelectual en Venezuela", en: Revista Propiedad Intelectual (vol. 8 № 12), pp. 10-33.

FERNÁNDEZ, Pura (1998): "En torno a la edición fraudulenta de impresos españoles en Francia: la Convención Literaria Hispano-Francesa (1853)", en: Estudios de Literatura Española de los Siglos XIX y XX (Madrid, Consejo Superior de Investigaciones Científicas).

FfrenCH-DAVIS, Ricardo et al. (1984): "The Latin American Economies: 19501990", en: BethelL, Leslie (ed.), The Cambridge History of Latin America (Reino Unido, Cambridge University Press), tomo 6-1.

Fragoso, João Henrique da Rocha (2012): Direito de Autor e Copyright: Fundamentos Históricos e Sociológicos (São Paulo, Quartier Latin).

Franko, Patrice (2007): The Puzzle of Latin American Economic Development, $3^{\text {a }}$ edición (Maryland, Rowman \& Littlefield Publishers).

Garcia Llansó, Antonio (1901): Manual de la Propiedad Intelectual (Barcelona, Tipografía de Luis Tasso).

Gargarella, Roberto (2013): Latin American Constitutionalism 1810-2010 (Nueva York, Oxford University Press).

Gervals, Daniel (2008): The TRIPS Agreement: Drafting, History and Analysis, $3^{\text {a }}$ edición (Londres, Thomson Reuters).

Ginsburg, Jane C. (1990): "A Tale of Two Copyrights: Literary Property in Revolutionary France and America", en: Tulane Law Review (vol. 64), pp. 991-1031.

Ginsburg, Jane C. y Kernochan, John M. (1988-1989): "One Hundred and Two Years Later: The U.S. Joins the Berne Convention", en: Columbia-VLA Journal of Law \& the Arts (vol. 13), pp. 1-38.

Glade, William (1984): "Latin America and the International Economy: 18701914", en: BethelL, Leslie (ed.), The Cambridge History of Latin America (Reino Unido, Cambridge University Press), tomo 4.

Goldbaum, Wenzel (1954): Convención de Washington sobre el Derecho de Autor en Obras Literarias, Científicas y Artísticas: Estudio Sistematizado y Comentarios (Quito-Ecuador, Casa Editora Liebmann). 
Gómez Velasco, Xavier (2003): Patentes de invención y derecho de la competencia económica (Quito-Ecuador, Universidad Andina Simón Bolívar).

Gompel, Stefvan (2010): "Les Formalités Sont Mortes, Vive les Formalités! Copyright Formalities and the Reasons for their Decline in Nineteenth Century Europe", en: Deazley, Ronan et al. (ed.), Privilege and Property: Essays on the History of Copyright (Cambridge, Open Book Publishers).

Guzmán BRITo, Alejandro (2005): "Los Derechos sobre las Cosas Intelectuales o Producciones del Talento y del Ingenio", en: Guzmán Brito, Alejandro, Estudios dogmáticos de Derecho Civil (Valparaíso-Chile, Ediciones Universitarias de Valparaíso).

Hagopian, Frances y Mainwaring, Scott P. (ed.) (2005): The Third Wave of Democratization in Latin America: Advances and Setbacks (s.l.i., Cambridge University Press).

Halperín Donghi, Tulio (1984): "Economy and Society in Post-Independence Spanish America", en: BethelL, Leslie (ed.), The Cambridge History of Latin America (Reino Unido, Cambridge University Press), tomo 3.

Harvey, Edwin R. (1993): Derecho Cultural Latinoamericano: Centro América, México y Caribe (Buenos Aires, OEA-Depalma).

Helfer, Laurence R. y Alter, Karen J. (2008-2009): “The Andean Tribunal of Justice and its Interlocutors: Understanding Preliminary Reference Patterns in the Andean Community", en: New York University Journal of International Law and Politics (vol. 41, No 4), pp. 871-930.

Helfer, Laurence R. et al. (2009): "Islands of Effective International Adjudication: Constructing an Intellectual Property Rule of Law in the Andean Community", en: American Journal of International Law (vol. 103), pp. 1-47.

Hemmungs Wirtén, Eva (2010): "Colonial Copyright, Postcolonial Publics: the Berne Convention and the 1967 Stockholm Diplomatic Conference Revisited", en: SCRIPTED (vol. 7), pp. 532-550.

Howsam, Leslie y Raven, James (ed.) (2011): Books between Europe and the Americas: Connections and Communities, 1620-1860 (s.I.i., Palgrave-Macmillan).

Huerta Casado, Yolanda (1998): "El Tratado de Libre Comercio en Materia de Propiedad Intelectual y sus Repercusiones en América Latina", en: BECERRA Ramírez, Manuel (ed.), Derecho de la Propiedad Intelectual: Una perspectiva trinacional (México, Instituto de Investigaciones Jurídicas-UNAM).

JAKSIC A., Iván (2011): Andrés Bello: La pasión por el orden, $3^{\text {a }}$ edición (Santiago de Chile, Edit. Universitaria). 
Johns, Adrian (2009): Piracy: The Intellectual Property Wars from Gutenberg to Gates (s.I.e., University Chicago Press).

_ (2010): "Language, Practice, and History", en: Bentry, Lionel et al. (eds.), Copyright and Piracy: An Inderdisciplinary Critique (Reino Unido, Cambridge University Press).

KHAN, Zorina (2007): "La piratería de derechos de autor y el desarrollo: Evidencia de los Estados Unidos en el Siglo XIX", en: Revista de Economía Institucional (vol. 9, No 17), pp. 21-54.

KeEN, Benjamin y Haynes, Keith (2004): A History of Latin America, $7^{\text {a }}$ edición (Boston, Houghton Mifflin Co.).

Kennedy, Kevin C. (2004): "Introduction", en: Kennedy, Kevin C. (ed.), The First Decade of Free Trade in North America (Nueva York, Transnational Publishers).

KuPferman, Theodore R. (1958-1959): "The Universal Copyright Convention Analized from the Inter-American Point of View", en: Bulletin of the Copyright Society of the U.S.A. (vol. 6), pp. 227-231.

Ladas, Stephen P. (1938): The International Protection of Literary ad Artistic Property (Nueva York, The Macmillan Co.).

(1940-1941): "Inter-American Copyright", en: University of Pittsburgh Law Review (vol. 7), pp. 283-297.

LAFAYE, Jacques (1984): "Literature and Intellectual Life in Colonial Spanish America", en: Bethell, Leslie (ed.), The Cambridge History of Latin America (Reino Unido, Cambridge University Press), tomo 2.

LaGo, Tomás (1934): "Los Derechos de Autor y el Porvenir del Libro Chileno", en: Anales de la Universidad de Chile (vol. 14), pp. 142-166.

LASTARRIA, José Victorino (1906): Obras completas: Estudios políticos i constitucionales (Santiago, Impr. Barcelona).

- (2001): Recuerdos literarios (1878) (Santiago, LOM Ediciones).

Lauria-Santiago, Aldo (2008): "Land, Labor, Production, and Trade: NineteenthCentury Economic and Social Patterns", en: Holloway, Thomas H. (ed.), A Companion to Latin American History (s.l.i., Blackwell Publishing).

LIPSZYC, Delia et al. (1998a): La protección de los derechos de autor en el sistema interamericano (Bogotá, Universidad Externado de Colombia-Dirección Nacional de Derechos de Autor).

(1998): "Esquema de la protección internacional del Derecho de Autor por las Convenciones del Sistema Interamericano", en: LiPszYC et al., La 
protección de los derechos de autor en el Sistema Interamericano (Bogotá, Universidad Externado de Colombia-Dirección Nacional de Derechos de Autor).

LIPSZYC, Delia (1999): Copyright and Neighbouring Rights (París, UNESCO Publishing).

LoRedo Hill, Alfonso (2000): Nuevo Derecho Autoral Mexicano (México, Fondo de Cultura Económica).

ManzuY-Diniz Silva, Andrée (1984): "Portugal and Brazil: Imperial Reorganization:

1750-1808", en: BethelL, Leslie (ed.), The Cambridge History of Latin America (Reino Unido, Cambridge University Press), tomo 1.

Martínez Baeza, Sergio (1982): El libro en Chile (Santiago, Biblioteca Nacional). MARTINS, Samuel (1906): Direito Autoral (Recife, Officinas da Livraria Franceza).

Mateos AlarCón, Manuel (1887): Estudios sobre la propiedad literaria, dramática y artística (México, Imprenta de Francisco Díaz de León).

MATTA, Guillermo (1873): "Revista Literaria Américana", en: El Americano, № 6 (Paris, 28 de abril de 1873), p. 1.

MeAde, Teresa A. (2010): A History of Modern Latin America: 1800 to the Present (Singapur, Wiley-Blackwell).

MeDina, José Toribio (1958): La historia de la imprenta en los antiguos dominios españoles de América y Oceanía (Santiago de Chile, Fondo Histórico y Bibliográfico José Toribio Medina).

Mestre, José Manuel (1863): De la propiedad intelectual (La Habana, La Antilla). Mirosevic Verdugo, Camilo (2007): "Origen y evolución del derecho de autor: con especial referencia al Derecho chileno", en: Revista de Derecho de la Pontificia Universidad Católica de Valparaíso (vol. 28, № 1), pp. 35-82.

Mirow, Matthew C. (2004): Latin American Law: A History of Private Law and Institutions in Spanish America (Austin, University of Texas Press).

MizukAmı, Pedro (2007): Função Social da Propriedade Intelectual: Compartilhamento de Arquivos e Direitos Autorais na CF/88 (São Paulo, Pontifícia Universidade Católica).

_ et al. (2010): "Exceptions and Limitations to Copyright in Brazil: A Call for Reform", en: Shaver, Lea (ed.), Access to Knowledge in Brazil (Reino Unido, Bloomsbury).

Monsalve, Quintiliano (1967): "La Conferencia de Estocolmo sobre Propiedad Intelectual", en: Revista de Derecho y Ciencias Sociales (vol. 140), pp. 81-84. 
MOuchet, Carlos (1969): El Derecho de Autor internacional en una encrucijada (Buenos Aires, Sociedad de Autores y Compositores de Música).

NDIAYE, Ndéné (1986-1987): "The Berne Convention and Developing Countries", en: Columbia-VLA Journal of Law \& the Arts (vol. 11), pp. 47-56.

Noriega, Mariano José (1907): La propiedad literaria y caso jurídico (México, Antigua Imprenta de Murguia).

Ocampo, Telesforo A. (1900): Dos problemas jurídicos en materia de propiedad literaria (México, Imprenta del Gobierno).

O'Keefe, Thomas Andrew (1996): "How the Andean Pact Transformed Itself into a Friend of Foreign Enterprise", en: International Lawyer (vol. 30), pp. 811-824.

OLIAN, Jr., Irwin A. (1974): "International Copyrights and the Need of Developing Countries: The Awakening at Stockholm and Paris", en: Cornell International Law Journal (vol. 7, № 2), pp. 81-112.

Oquendo, Ángel R. (2006): Latin American Law (Nueva York, Foundations Press).

Organization of American States-General Secretariat (1984a): Copyright Protection in the Americas-Argentina (Nueva York, Oceana Publications).

_ (1984b): Copyright Protection in the Americas-Mexico (Nueva York, Oceana Publications, 1984).

Oruela, Calixto (1889): Estudios y artículos literarios (Buenos Aires, Impr. de Pablo E. Coni é Hijos).

PABÓN CADAVID, Jhonny Antonio (2009): “Aproximación a la Historia del Derecho de Autor: Antecedentes Normativos", en: Revista La Propiedad Inmaterial (vol. 13), pp. 59-104.

(2010): De los privilegios a la propiedad intelectual: La protección en Colombia a las obras literarias, artísticas y científicas en el siglo XIX (Colombia, Universidad Externado de Colombia).

PACón, Ana María (2003): "La protección del derecho de autor en la comunidad andina", en: Brewer-CaríAs, Allan-Randolph (ed.), Derecho Comunitario Andino (Lima, Fondo Editorial Pontificia Universidad Católica del Perú).

Pan American Union (1962): Protección del Derecho de Autor en América, $3^{\text {a }}$ edición. (Washington, Unión Panamericana).

Paranagua, Pedro y Branco, Sérgio (2009): Direitos Autorais (Rio de Janeiro, Fundação Getúlio Vargas).

Peña, Daniel y Carmona, María Catalina (2011): Intellectual Property Law in Colombia (Holanda, Kluwer Law International). 
PlazAs, Arcadio (1984): Estudios sobre Derecho de Autor: Reforma legal colombiana (Bogotá, Temis).

QuesADA, Ernesto (1904): La propiedad intelectual en el Derecho Comparado (Buenos Aires, Librería de J. Menéndez).

RabASA, O. (2000): Historia de las constituciones mexicanas (México, Instituto de Investigaciones Jurídicas-UNAM). 